\title{
أثر المدخل الإيكولوجي والمقارن في دراسة الإدارة العامة
}

* د. محمد محمود عبد العال حسن

\section{ملخص}

تهدف هذه الدراسة إلى فحص المدخلين الإيكولوجي والمقارن باعتبارهما أحد أهم المداخل التي ساهمت في تطوير دراسة الإدارة العامة. وسوف تركز الدراسة على تقييم العوامل البيئية المختلفة وتأثيرها على بلى النظام الإداري في أي مجتمع بغض النظر عن طبيعة هذه العوامل سواء كانت اقتصادية، اجتماعية،

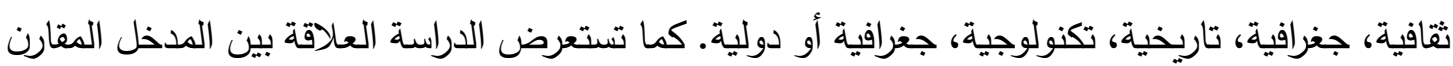
والإدارة العامة من خلال تسليط الأضواء على مدرستين هامتين اصطبغتا كل منها بصبغة، واتخذت

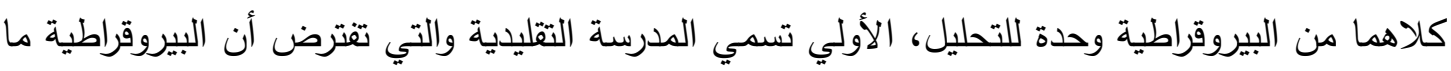
هي إلا نتاج العوامل والمتغيرات في محيط نشاط الإدارة وأن محاولة التغيير لا تتأتى إلا بالتحكم في ذلك الك الته المحيط. والمدرسة الثانية تسمي بالمدرسة الحديثة وتري أن الإدارة ما هي إلا نظام فرعي يمكن تغييره في الأطر المحيطة بحيث إذا بدلنا وطورنا نظم التدريب والتعيين سوف يتغير النظام ككل. وتقدم الدراسة رؤية تقييمية للمدخل الإيكولوجي ومناقشة مفهوم المنهج المقارن كما تم عرض مشكلات وصعوبات دراسة الإدارة العامة المقارنة، وخاتمة للدراسة. الكلمات الدالة: الإدارة العامة المقارنة - المدخل الإيكولوجي - المنهج المقارن - البيروقراطية - الإدارة

\section{Abstract \\ The Effect of the Ecological and Comparative approach in the Study of Public Administration}

This study aims at exploring the concept of the ecological approach and its meaning. The Ecological approach is considered one of the major contributions in the field of public administration. This study will focus on the different ecological factors that may affect the administrative system in any society, regardless of the nature of these factors, political, economic, social, cultural, geographical, historical, technological or international.

The study would also examine the relationship between the ecological approach and public administration by highlighting two main streams of thoughts, The first is the Traditional School, which argues that bureaucracy is an output of the factors and variables in the environment of the administrative system, where any change in the administrative system has to go through controlling this environment. The second of which is the Modern School that praises the administrative system is by definition a subsystems which can be changed through, recruitment and training mechanisms. Then the study will evaluate the ecological approach form a comparative administrate prospective. The problems and difficulties of the comparative public administration study were also presented, and a conclusion of the study.

Key words: Comparative public administration - ecological approach - comparative approach - bureaucracy - public administration. 


\section{مقدمة}

حَفَلَ علماء الإدارة العامة بالجمع بين جناحيها: كممارسة عملية، ومجال أكاديمي علمي، ومن ثم

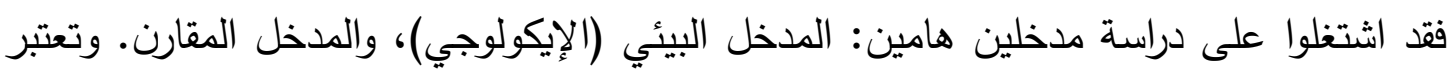

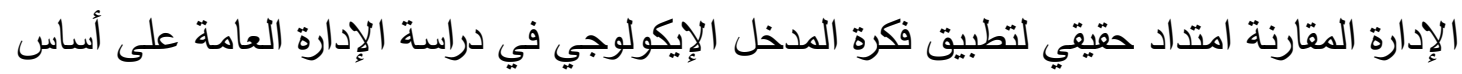
مقارن. وسوف تعرض الدراسة لهذين المدخلين. وقد أدى تطور دراسة الإدارة العامة إلى بروز أربعة مداخل أساسية (Approaches) لدراسة

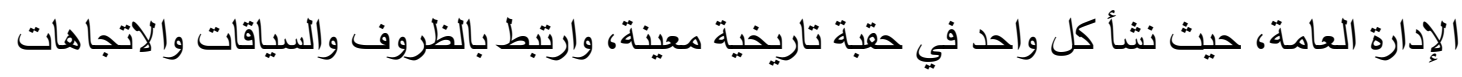

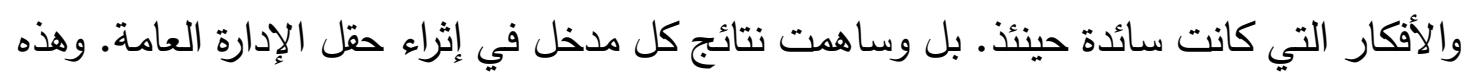

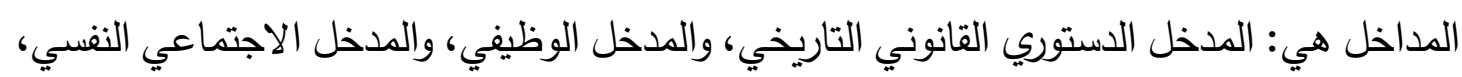

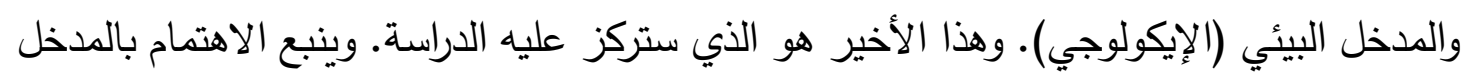

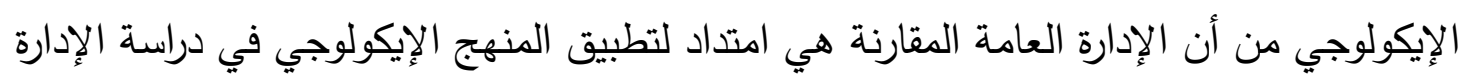

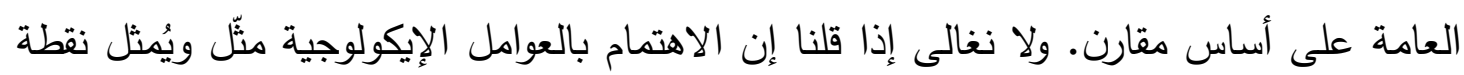
البداية لفهم الإدارة العامة بشكل أوضح.

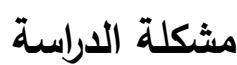
بما أن علم الإدارة العامة يكترث بدراسة الجهاز الإداري وتحسين كفاءته وفعاليته بصورة مستمرة،

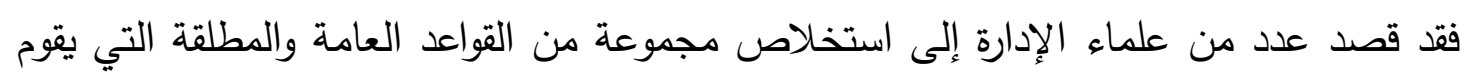

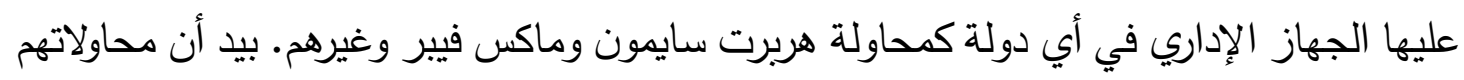
جاءت محدودة وجامدة ولا تصلح للتطبيق على كل المؤسسات. ولما كانت بعض مبادئ الإدارة العامة وقواعدها ثمرة لدراسات الإدارة العامة في البيئات المختلفة

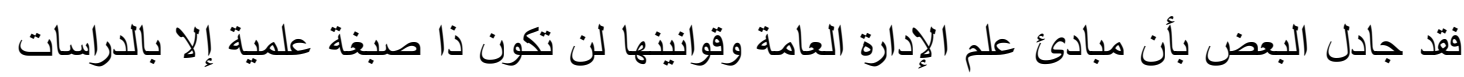

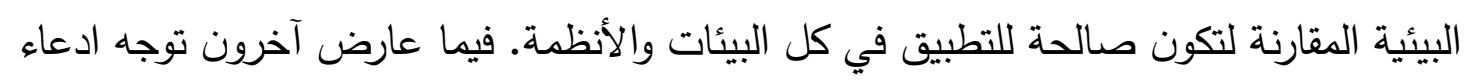

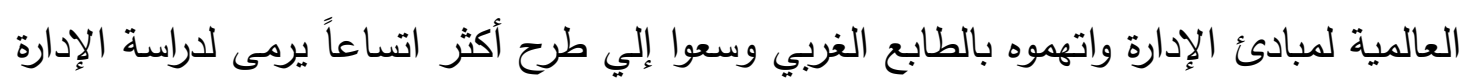
العامة وفهمها في مناطق ثقافية ودول مختلفة. وفي هذا السياق، تحاول الدراسة الإجابة على عدد من التساؤلات كما يلي:

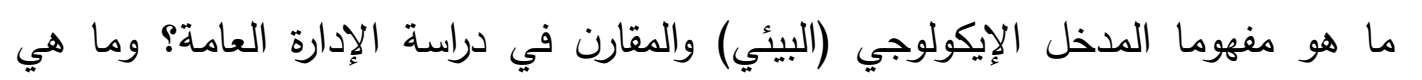

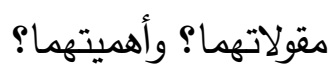
ما هي أهم العوامل البيئية المؤثرة في الإدارة العامة؟ وكيف أثر المنهج البيئي والمقارن على العي

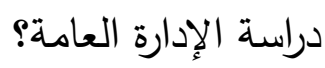
ما هي عناصر الاستمرارية والتغير في تطور الدراسات المقارنة للإدارة العامة؟ وكيف انعكس التطور على دراسة الإدارة العامة؟ هارئ 
• منهجية الدراسة أبرز مشكلات وصعوبات دراسة الإدارة العامة المقارنة؟ ولماذا؟ تستخدم الدراسة المنهج الوصفي والتحليلي فيما يرتبط بالخلفية النظرية للمنهين الإيكولوجي (البيئي) والمقارن، وذلك بالاستفادة من مراجعة عدد من الأدبيات ذات الصلة بالموضوع لاستخراج ما تتضدنه من معانِ فيما يرتبط بالمفهومين. وتسعى الدراسة لفحص وتحليل معالم المنهجين الإيكولوجي والمقارن وأهميتها وأبرز روادهما ومساهماتهم، والعوامل البيئية المختلفة وأثرها على نمط الإدارة العامة. وتتناول الدراسة كذللك مشكلات دراسة الإدارة العامة المقارنة. ولا تقتصر الدراسة على السرد التاريخي للمنهجين وأثرهما بل ستحاول رصد الأبعاد المتباينة للمنهجين في إطار الفكر والتطبيق. فروض الدراسة تفترض هذه الدراسة فرضين أساسيين، وهما كالتالي: - توجد علاقة ارتباط موجبة بين فعالية استخدام المنهج البيئي والمقارن وتحسين دراسة الإدارة العامة. - يمثل المنهج البيئي والمقارن ملمحاً جوهرياً في تطوير حقل الإدارة العامة المقارنة. تقسيم الاراسة تنقسم الدراسة إلى سبعة أجزاء رئيسية. يتناول الجزء الأول مفهوم المدخل الإيكولوجي وأهميته ودوره في تطوير علم الإدارة العامة وأهم رواده. ويعرض الجزء الثاني لأهم العوامل البيئية التي تؤثر في طبيعة الإدارة، الأمر الذي يمهذ ثالثاً لمناقشة أثر المنهج الإيكولوجي على دراسة الإدارة العامة. ويليه الجزء الرابع والذي يقدم الباحث فيه رؤية تقييمية للمنهج الإيكولوجي. ويتطرق الجزء الخامس إلى استعراض المنهج المقارن من خلال تعاريفه وأهدافه في دراسة الإدارة العامة. ويحاول الجزء السادس استكثاف الثابت والمتغير في تطور الدراسة المقارنة للإدارة العامة، وأخيراً يوضح أبرز المشكلات والصعوبات التي تعترض دراسة الإدارة العامة المقارنة.

أولاًَ- المدخل الإيكولوجي البيئي Ecological Approach : المفهوم والأهمية والرواد من الهام قبل الولوج إلي شرح المدخل البيئي وعلاقته بعلم الإدارة والدور المحوري الذي لعبه في دفع هذا العلم وتطويره التطرق إلى تعريف هذا المدخل وأهميته ورواده على النحو التالي: (1)في مفهوم المدخل الإيكولوجي -البيئي يُعرَف هذا المدخل باسم المدخل البيئي أو الإيكولوجي، وهو "يتقق مع المداخل السابقة في اهتمامه بدراسة العوامل الاجتماعية والنفسية والإنسانية"(محمود، 14: 1997). و "كلمة إيكولوجي (Ecology) مشتقة من الأصل الإغريقي (Ekos) أي ما يحيط بالمرء فيصبح مسكنه، وكلمة (Logy) معناها علم، والكلمة كلها تعني العلم الذي يهتم بالمحيط الذي يصبح 
مسكناً للموضوع محل الدراسة، أي أنه يهتم بالبيئة والعوامل التي تؤثر فيها. والكلمة مأخوذة من

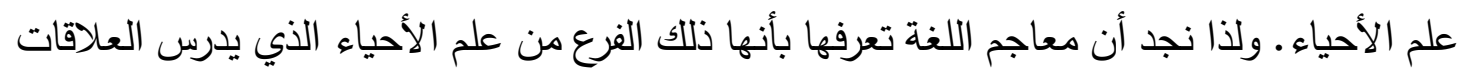

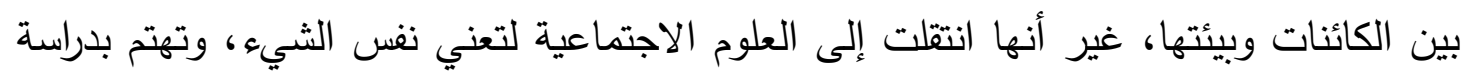

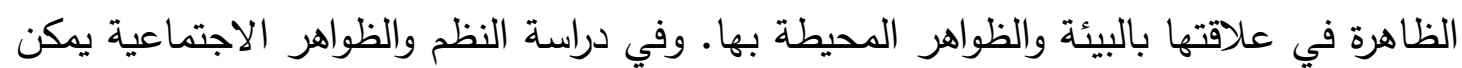
أن نعرف الإيكولوجي بأنه ذلك الفرع العلمي الذي يهتم بدراسة العلاقة المتبادلة بين النظم وبيئاتها،

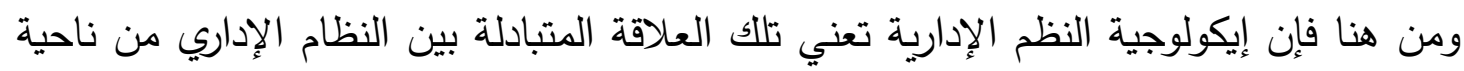

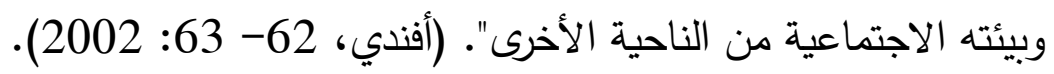

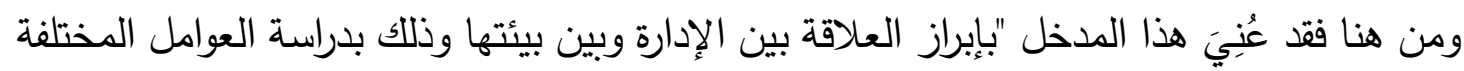

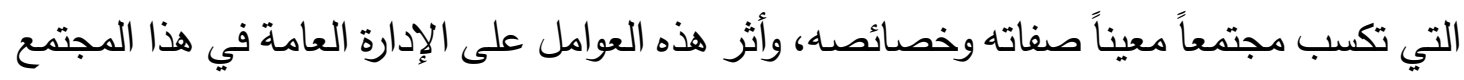

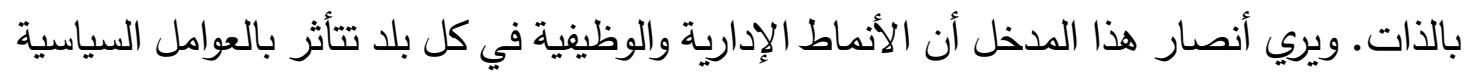

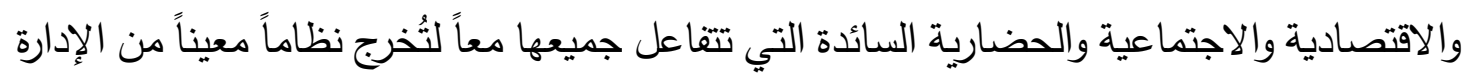

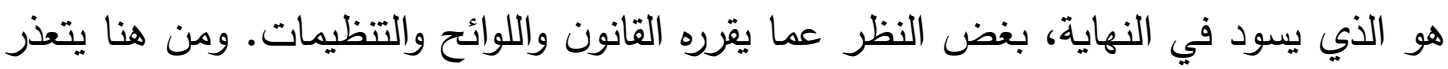

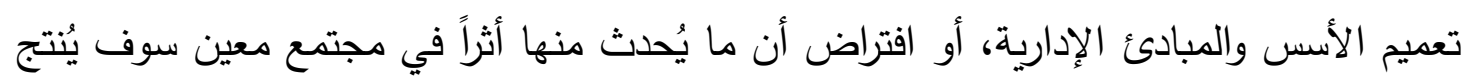

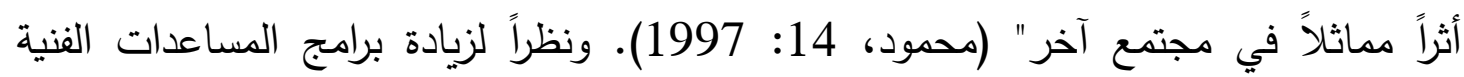

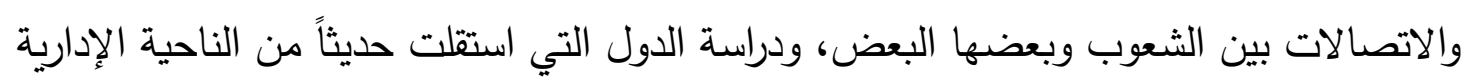
بدأ هذا المدخل يأخذ وضعه منذ الحرب العالمية الثانية.

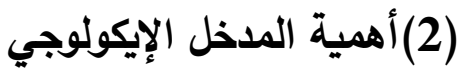
من الصعوبة أن "يتمكن نظام إداري من أن يقتبس بأكمله من حضارة أخري مختلفة. فلو أن تتظيماً

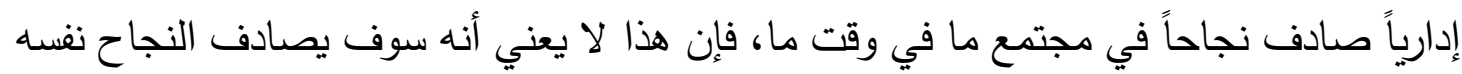

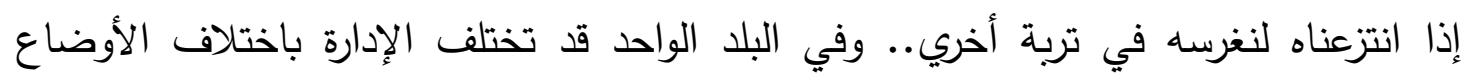

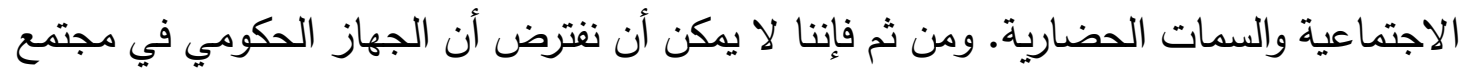

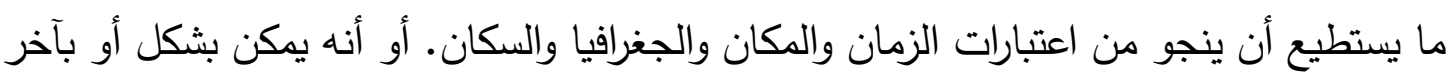

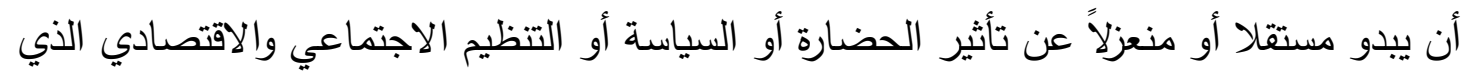

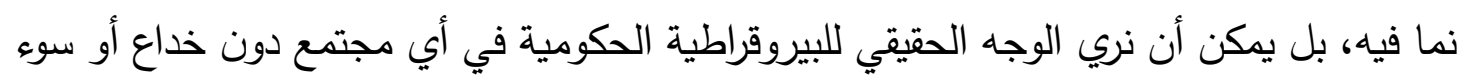

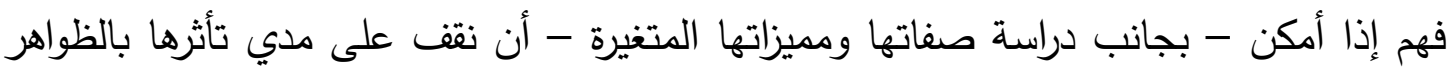

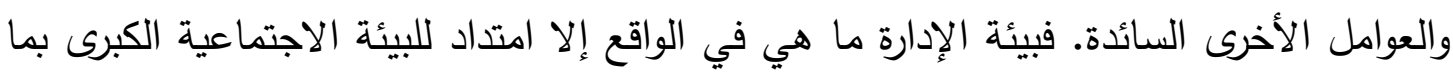

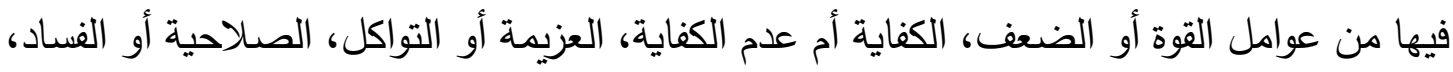

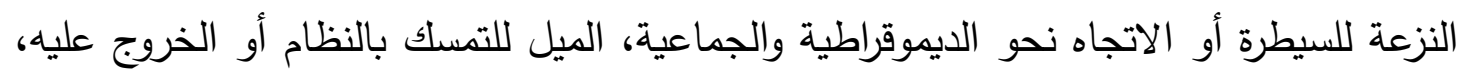

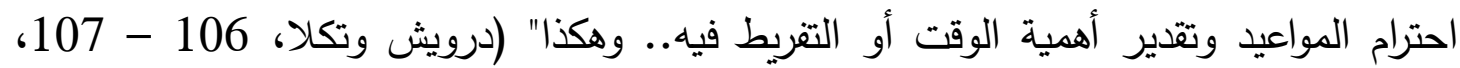




\section{(3)(أبرز رواد الدراسات الإيكولوجية - البيئية}

شكل مجموعة من الرواد الذين اهتموا بالبحوث البيئية أو المنهج الإيكولوجي في دراسة الإدارة العامة ما يُشبه بالتراكم المعرفي أو العلمي، مثل: جون جاوس، وجيمس فسلر ، وروبرت دال، وفريد رجز • وسوف نتناول بطريقة مختصرة مجهودات كل منهز كالتالي: بـات - جون جاوس Jone Merriman Gaus (1894- 1969) "نادى بضرورة دراسة العوامل البيئية في كل بلد حتي يمكن أن نصل إلى فهم حقيقي للسمات والصفات التي تميز أية حكومة ووظائفها وطريقة عملها وطبيعة علاقاتها . وتتضمن هذه العوامل المكان والسكان والتقدم العلمي والتقني، والقيم والعادات والتقاليد والرغبات والأفكار الشخصية والمحن والكوارث التي يمر بها المجتمع". (درويش وتكلا، 15، 1986). وقد نشر في العام 1935 بالاشتراك مع زملاءه دراسة بعنوان العوامل الإقليمية في التخطيط القومي والتنمية (Gaus، 1935) ثم في عام 1947 نشر كتاب بعنوان "تأملات في الإدارة العامة" (Gaus، 1947) من ستة فصول، تتاول

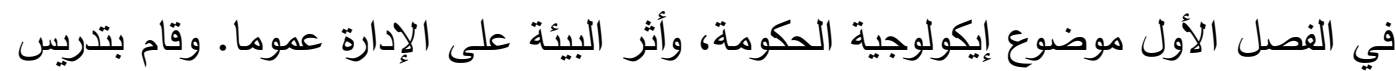
دور البيئة وأثرها على الإدارة العامة في جامعة هارفارد في الأربعينيات والخمسينيات. وقد "اعتمد على أعمال علماء الاجتماع خلال العشرينات الذين كانوا يبحثون في علاقة الحياة الإنسانية بالبيئة المحيطة، والذين استعانوا بدورهم بعلماء النبات والحيوان محاولين تفسير كيفية تكيف الأعضاء النباتية والحيوانية للبيئات التي تعيش فيها، وقد كان هم جوس منصرفاً إلى لإنى فهم الإدارة العامة الأمريكية المعاصرة، لذا فقد درس قائمة من العوامل التي وجدها ذات فائدة وخاصة، الناس والمكان والتكنولوجيا الطبيعية والتكنولوجيا الاجتماعية والرغبات والأفكار الشخصية"(هيدي، 51). - - جيمس فسلر James William Fesler (1911-2005) ألف مع صديقه دونالد كيتل كتاباً بعنوان الإقليم والإدارة "Fesler and Kettl) "Area and Administration" 1964)، وأكدا فيه على أهمية عنصر البيئة ودورها الفاعل في الإدارة العامة. كما قام بتأليف كتب أخري مثل كتابه: الإدارة العامة - النظرية والممارسة، وعناصر الإدارة العامة، وكان تركيزه في أغلب كتاباته منصب على البيئة. روبرت دال Robert Alan Dahl (1915-2014) حيث نشر مقالة في مجلة مراجعة The Science of Public Administration Three الإدارة العامة، بعنوان: (Problems أن هنالك صلة وطيدة بين الإدارة العامة ومحيطها الاجتماعي الذي تشتغل فيه. ويمكن من خلال الدراسات المقارنة التي تتجاوز حدود الدولة الواحدة الوصول في حقل الإدارة إلى علم له قواعد تتسم بالشمول والعمومية. ومن ثم فالبحث والدراسة لا يكونا منصبين فقط على بيئة 
اجتماعية بعينها لأن ذلك سينت ج قواعد مفككة وغير مترابطة. وأشار "دال" إلى استحالة نقل

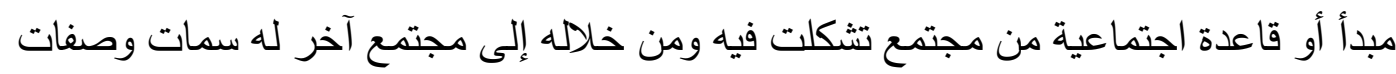

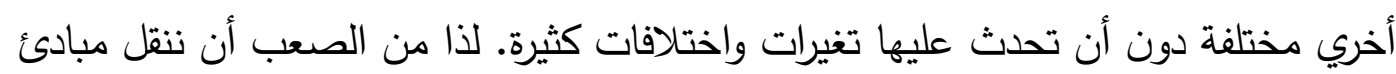
سياسية أو إدارية معينة من مجتمع له سياقه التاريخي والثقافي وظروفه الاقتصادية والسياسية والحضارية ونحاول تطبيقه في مجتمع آخر وننتظر نفس النتائج. The ecology " فرد رجز Fred W. Riggs of public administration المتحدة، وتايلند، والفلبين. وهي نماذج لدول صناعية حديثة، ودول زراعية تقليدية، ودول نامية

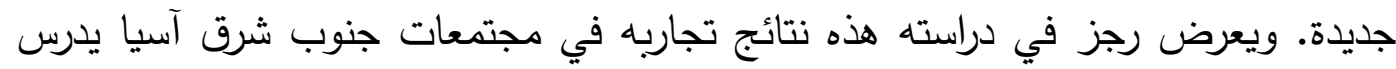

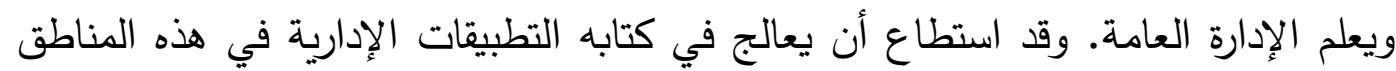

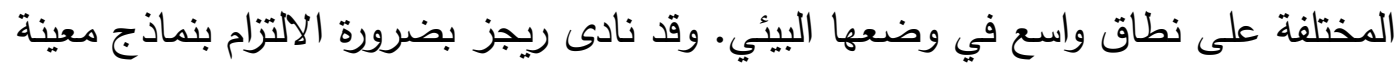

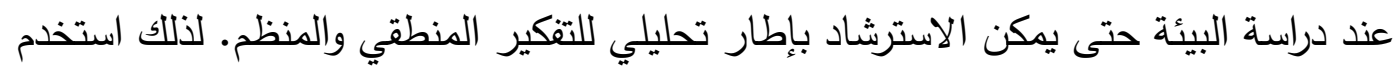
في دراسته نماذج نظرية لتصنيف المجتمعات، ولتقسيم أنظمة العمل فيها، لتكون أدوات للتحليل

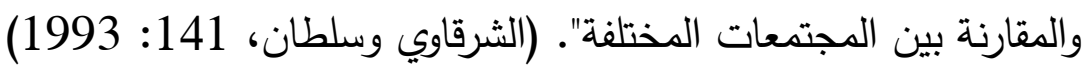
وقد "عمل رجز على تتمية هذا الدذخل، وفصل اتجاهاته المختلفة والتحولات التي طرأت عليه من اتجاه يقوم على تقديم نماذج إدارية - والذي ظهر في المراحل الأولي من دراسة الإدارة

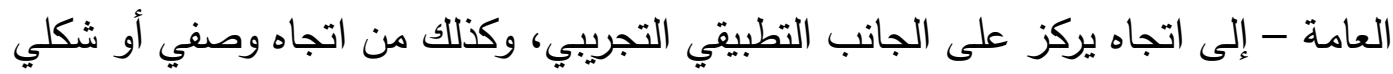

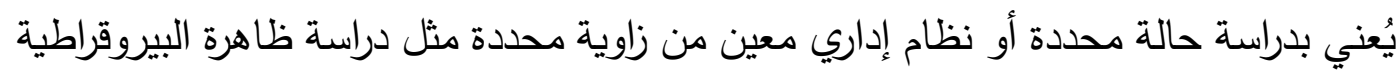

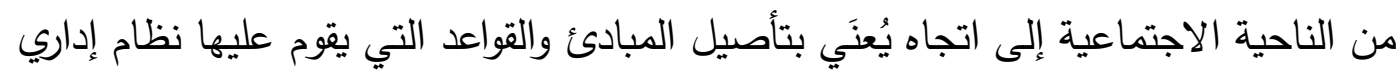

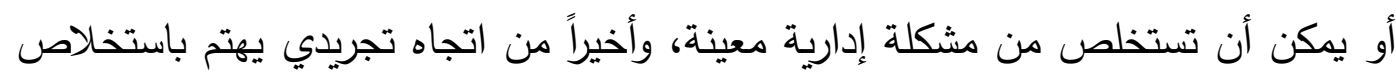

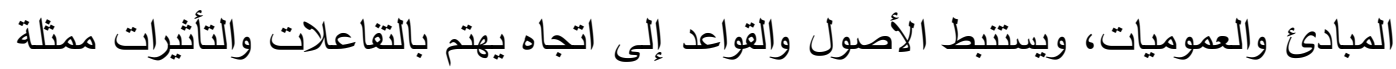

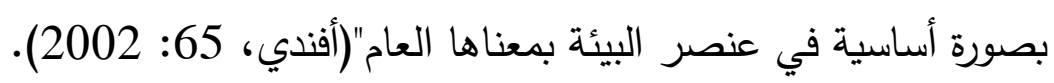
جماعة الإدارة المقارنة، تألفت هذه الجماعة في العالم 1960 كفرع من الجمعية الأمريكية للإدارة العامة، ونجحت في الحصول على تمويل من مؤسسة فورد ساهم في تطورها ونموها،

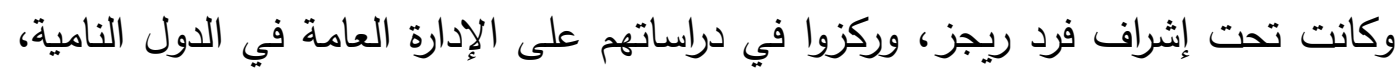

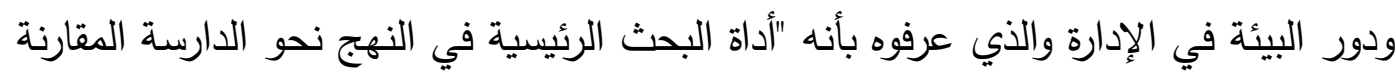

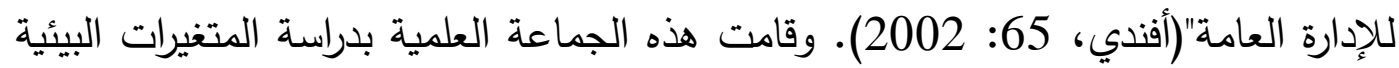

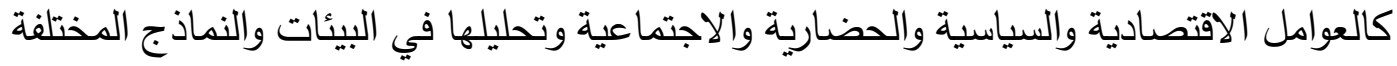

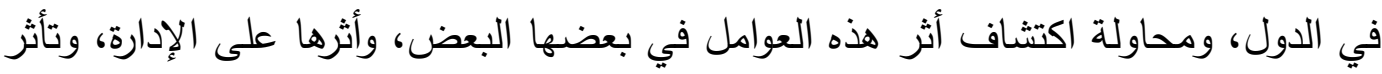

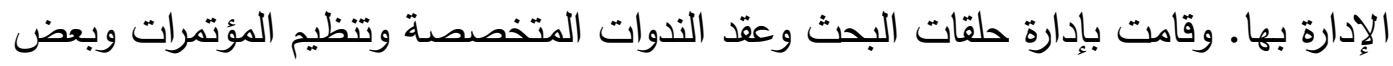


المشاريع التعليمية والتجريبية. وتبلورت هذه النتائج فيما تم نشره حول موضوع الإدارة العامة

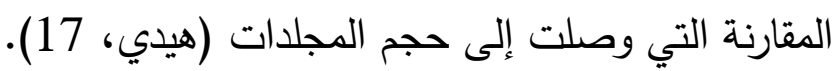

$$
\begin{aligned}
& \text { ثانيًا- العوامل البيئية وأثرها على الإدارة }
\end{aligned}
$$

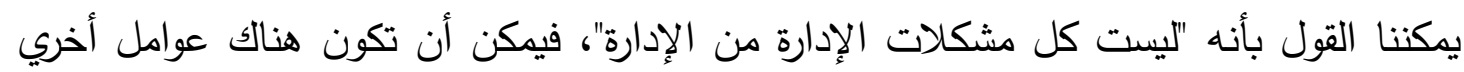

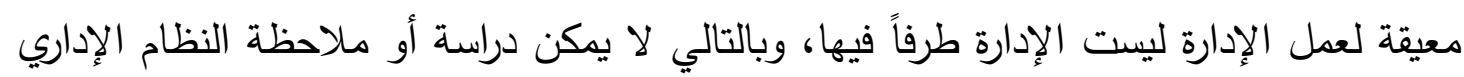

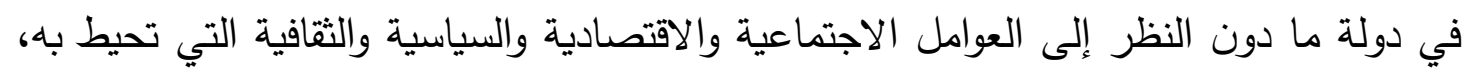

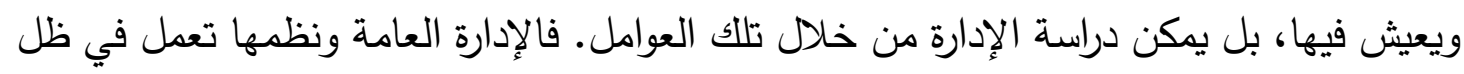

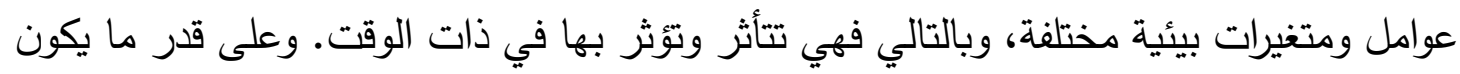

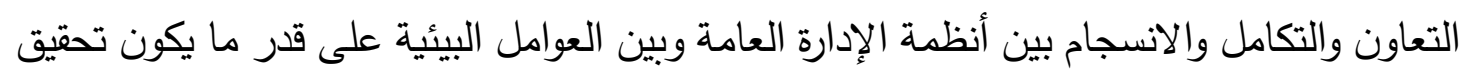

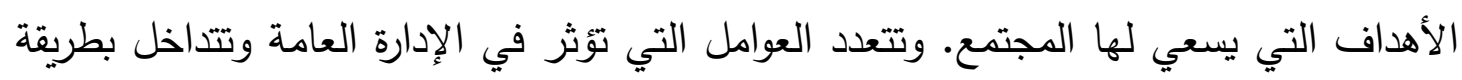

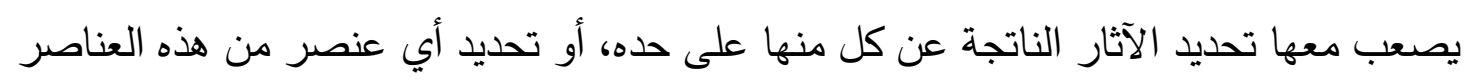

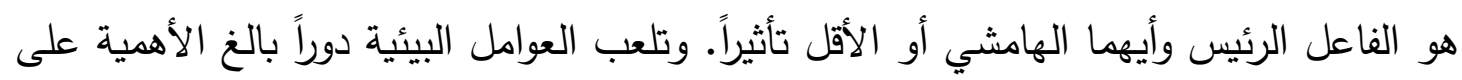

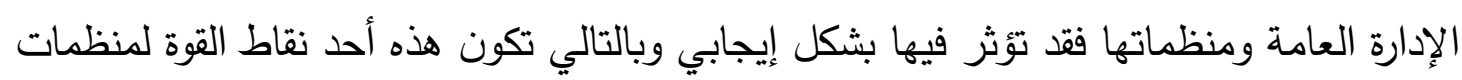
الإدارة العامة، وقد تؤثر بطريقة سلبية وتبدو في صورة قيود ومعوقات تمارسها البيئة على الإدارة

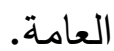
لذا فمن الضروري عرض بعض العوامل البيئية المؤثرة في الإدارة العامة، ويوضح الشكل رقم (1)

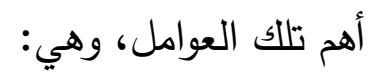
العوامل السياسية. ه العوامل الاقتصادية.

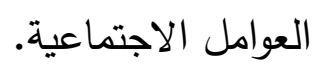
العوامل الثقافية. العوامل التاريخية. العوامل الجغرافية. العوامل التكنولوجية.

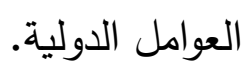




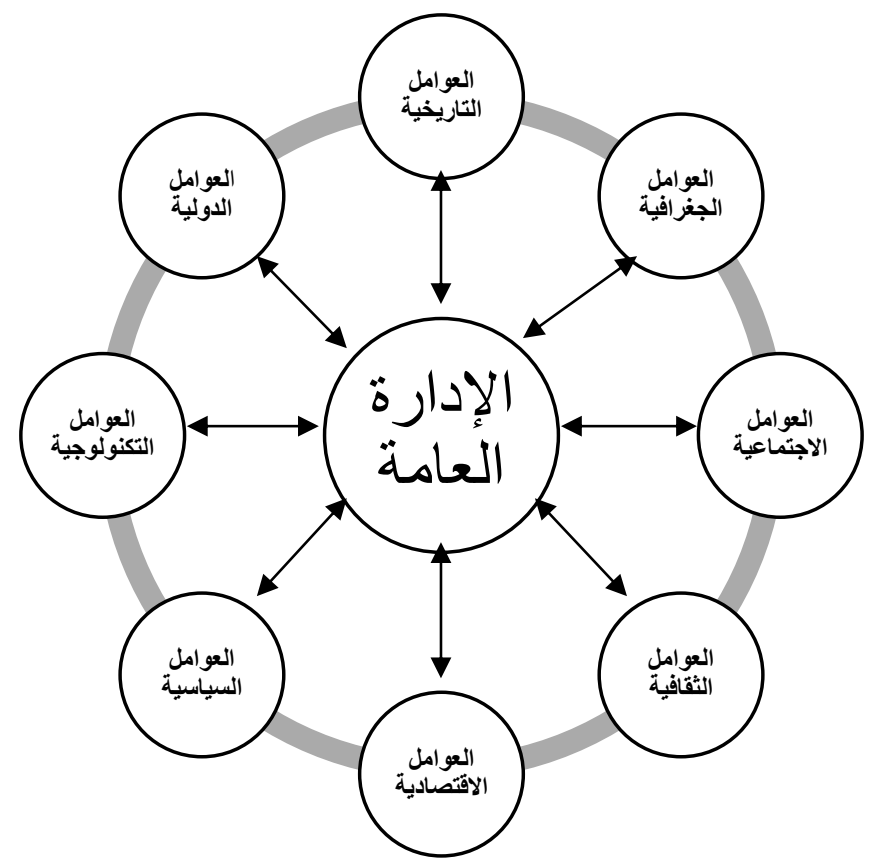

شكل (1): أثر العوامل البيئية المؤثرة في الإدارة العامة والعكس1

العوامل السياسية

تلعب العوامل السياسية دوراً في التأثير على أجهزة الإدارة العامة وتتفاعل معها، وتكون بينهما علاقات تأثير متبادل، وهذه العوامل السياسية المؤثرة على الإدارة العامة يمكن عرضها كالتالي: نظام الحكم: فلا ريب أن "نظام الحكم له أثره على الإدارة، وعلى مكانة الخدمة العامة التي تعمل في ظله، وعلى استقرارها"(محمود، 34: 1997)، فقد يوجد نظام ملكي أو جمهوري (برلماني أو رئاسي)، ومن ثم ستختلف طريقة استخدام السلطة وممارسة الحكم مما ينعكس على الإدارة العامة ومنظماتها بطريقة مباشرة، كما يوضحها جدول رقم (1) التالي: 
جدول (1): تأثير أنماط أنظمة الحكم على الإدارة العامة

\begin{tabular}{|c|c|c|}
\hline \multicolumn{3}{|c|}{ نظام الحكم وأثره على الإدارة العامة } \\
\hline \multicolumn{2}{|c|}{ 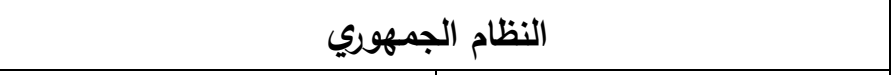 } & \multirow{2}{*}{ النظام الملكي } \\
\hline النظام البرلماني & النظام الرئاسي & \\
\hline رئيس الدولة هنا قد يكون ملك أو & 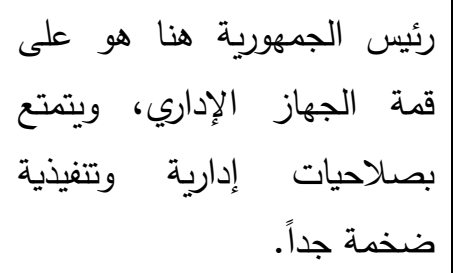 & 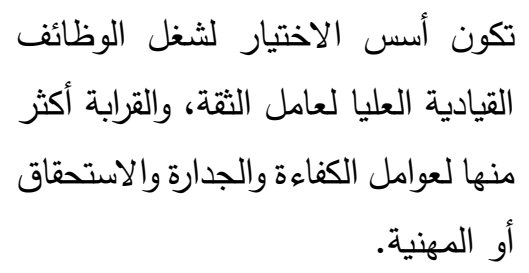 \\
\hline 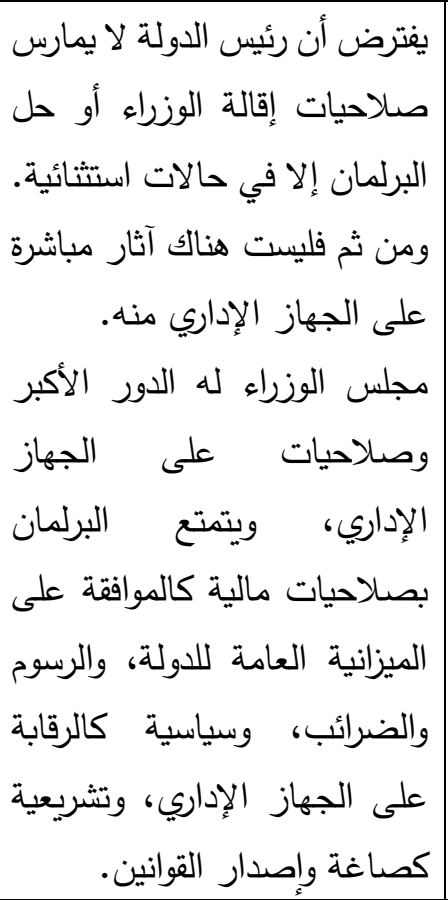 & 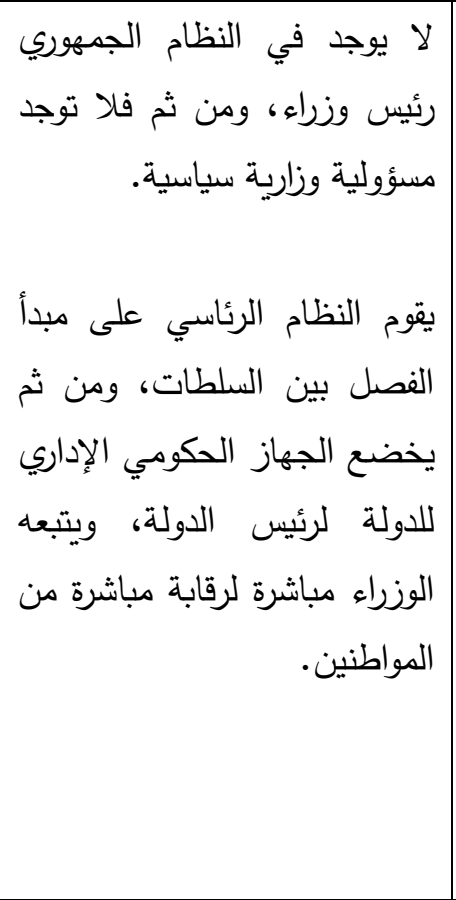 & 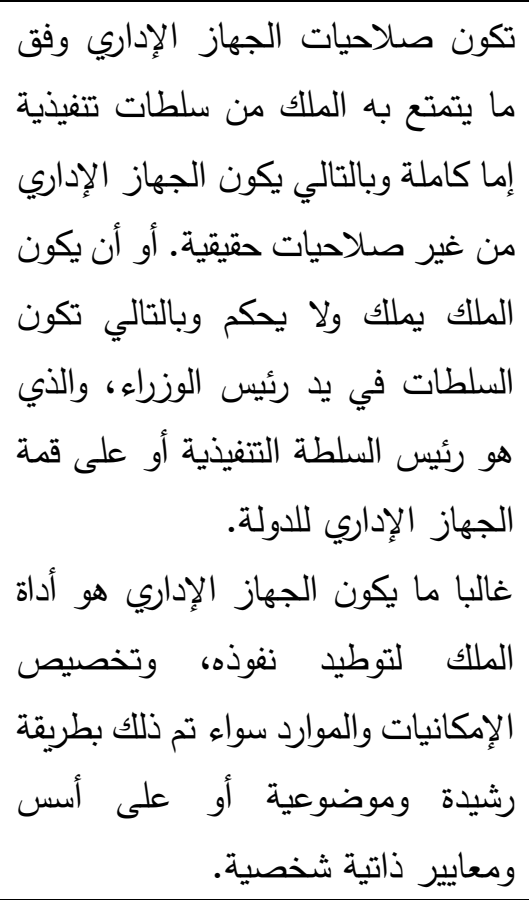 \\
\hline
\end{tabular}

المصدر: (النجار والمغربي، 136 - 147)، والجدول من إعداد الباحث.

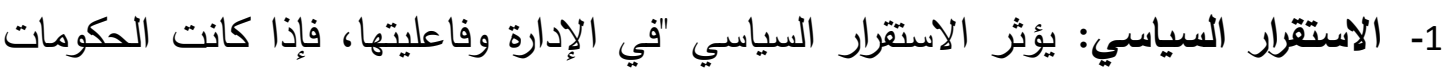

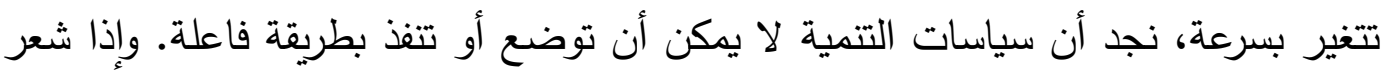

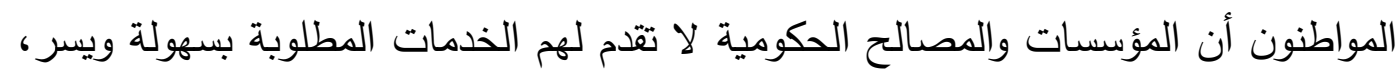

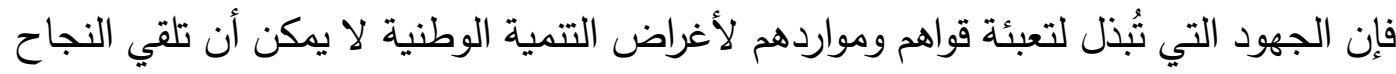

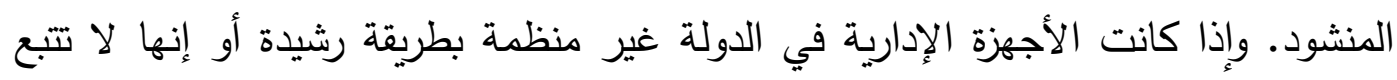
توجيهات القيادة السياسية، فإن خطط التتمية تصبح عديمة الجدوى"(النجار والمغربي، 34 - 35 35). وغالباً ما يترتب على تداول الحكم والسلطة بين الأحزاب في دولة ما اختلاف المصالح

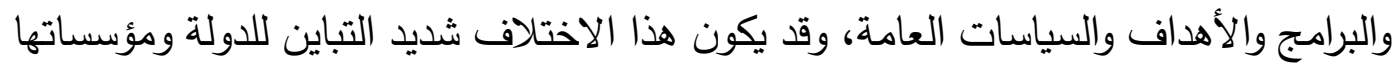
ووظائفها وهذا ينعكس على الإدارة العامة بلا ريب. 
2- المشاركة السياسية: هناك اختلاف بين نظم الحكم وفقاً لحجم المشاركة السياسية للمواطنين، "فدرجة المشاركة الديموقراطية لها تأثيرها البالغ على أداء وعلاقات أجهزة الإدارة العامة في

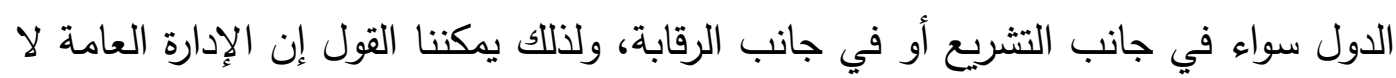
يمكن أن تزدهر إلا في مناخ ديموقراطي"(النجار والدغربي، 148) 3- أيديولوجية الدولة: "تتأثر منظمات الإدارة العامة من حيث تنظيمها واختصاصاتها بالفلسفة دئة التي تعتنقها السلطة السياسية الحاكمة بشأن تحديد وظيفة الدولة. حيث يمكن التفرقة بين حالتين، أولهما: أنه عند رغبة السلطة السياسية إحداث تغيرات واسعة في البنيان الاجتماعي والاقتصادي للمجتمع فإن ذلك يقودها إلى أن تعهد إلى منظمات الإدارة العامة بسلطات واسعة

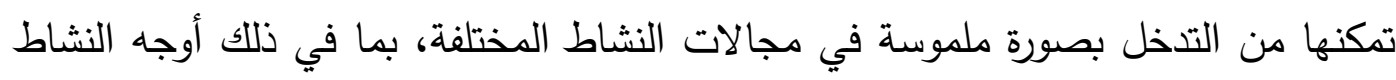

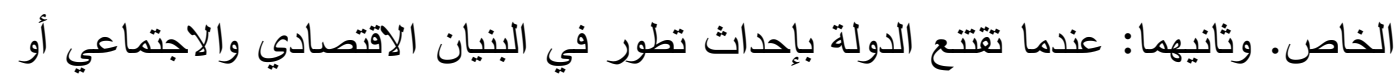
تترك هذا التطور لتفاعل وتوازن القوي الاقتصادية في المجتمع فإنها ستضيق اختصاصات الإدارة العامة".

4- شكل الدولة وتكوينها: تتقسم الدول إلى بسيطة أو مركبة. فإذا كانت دولة بسيطة فتأخذ أحد

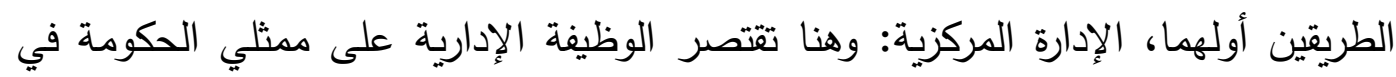
العاصمة. ثانيهما، اللامركزية الإدارية: وهنا يتم توزيع الوظائف الإدارية بين الحكومة المركزية والهيئات الإدارية الأخرى المحلية والتي تكون تحت رقابة الحكومة المركزية. أما إذا كانت الدولة مركبة بأشكالها المختلفة، فلكل شكل صورة إدارية. ففي الاتحاد الشخصي مثلا نجد أن طبيعة الإدارة تختلف من دولة لأخري، حيث أن كل دولة مشكلة للاتحاد تحتفظ بنظامها الداخلي. أما في الاتحاد الفعلي فإن بعض الوظائف الإدارية مثل السياسة الخارجية تكون موحدة. وبخصوص الاتحاد المركزي أو الفيدرالي فكل ولاية أو إقليم له الحق في تتظيم إداراته وفقاً لما تراه

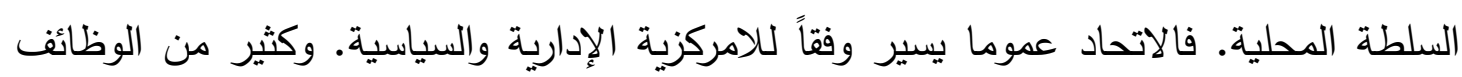
الإدارية لا تخضع لسلطة رئاسة الاتحاد.

\section{العوامل الاقتصادية}

"تثمل العوامل الاقتصادية في كل القوي والمتغيرات التي تئثر تأثيراً مباشراً أو غير مباشر على التى أجهزة الإدارة العامة"، (النجار والمغربي، 149)وهذه القوي والمتغيرات متعدد، يمكن أن نذكر منها أهم العوامل الاقتصادية المؤثرة على الإدارة العامة تتمثل في: الإده 
1- تركيب الهيكل الاقتصادي، حيث تتباين تراكيب الهياكل الاقتصادية من مجتمع لآخر مما

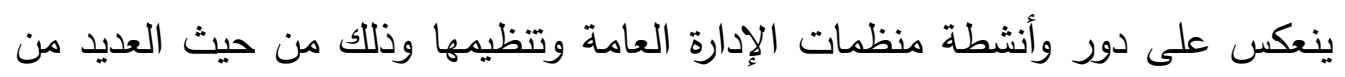

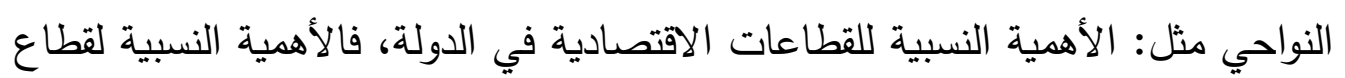
معين لها تأثيرها على منظمات وأجهزة الإدارة العامة، فعلى سبيل المثال إذا كان القطاع العيل الصناعي هو القطاع الرئيسي الذي يمثل عصب الحياة الاقتصادية في المجتمع، فمن الطبيعي أن تختص به وزارة على مستوي الدولة. ومدي الانتشار الجغرافي للهيكل الاقتصادي ويرتبط بهذا المتغير التشتت نمط واتجاهات منظمات وأجزة الإدارة العامة، فإذا كانت هناك درجة مرتفعة من الانتشاري الجغرافي حيث يتخصص كل إقليم في نثاط إنتاجي معين، أو في مورد معين، فإن جهود وأنشطة دإنها منظمات الإدارة العامة تتجه نحو تحقيق التكامل الاقتصادي القومي، وربط أقاليم الدولة

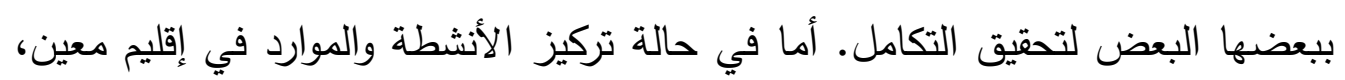

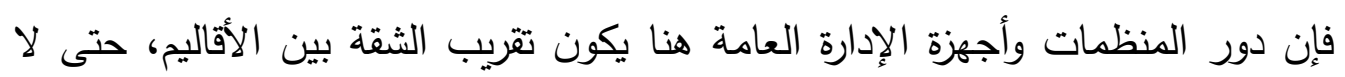
يكون هناك تفاوت في الدخل. ومستوي التقدم الاقتصادي حيث تختلف الدول من حيث درجة التقدم الاقتصادي، ومن ثم يختلف بالتالي هيكل أجزة ومنظمات الإدارة العامة في الدولة. فعندما تكون درجة التقدم الاقتصادي منخفضة يتسم البناء التنظيمي لأجهزة المنظمات العامة بالبساطة، بالإضافة إلى اختلاف وظائف هذه المنظمات. 2- نوعية النظام الاقتصادي المتبع، هناك عدد من النظم الاقتصادية المنتشرة حول العالم، فعندما يتبني النظام الاقتصادي الرؤية الرأسمالية فإن دور الحكومة سيكون محدود للغاية، وستقتصر مهامها على الوظائف الأساسية كالأمن والعلاقات الخارجية و..الخ، ومن ثن لثران تكون دور منظمات الإدارة العامة وهياكلها محدودة. بينما إذا كان النظام الاقتصادي

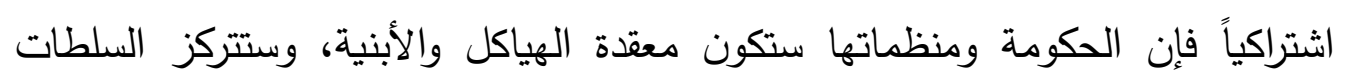
والقرارات الاقتصادية في يد الحكومة ومن ثم سيكون دور منظمات الإدارة العامة ضخم وكبير ومعقد.

3- مستوي توزيع الثروة والدخل، حيث أن هناك علاقة بين دور منظمات الإدارة العامة ومتوسط دخل الفرد ومستوي الثروة في المجتمع. فكلما كان متوسط دخل الأفراد في الدولة 
مرتفع فهذا يعني قدرة الحكومة على فرض الضرائب لتمويل مواردها وبالتالي قدر أكبر

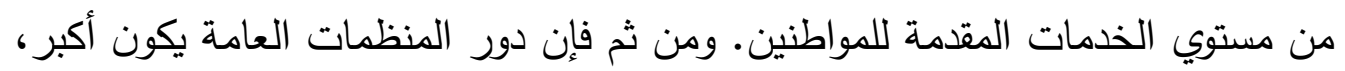
فضلا عن حرفتيه ومهنتيه لجمع الضرائب. والعكس حينما يكون متوسط دخل الأفراد متدني وتعجز الدولة عن جباية الضرائب، سينعكس هذا على مستوي الخدمات التي تقدمها الدول للمواطنين بالسلب. ومن الملاحظ أن رواتب الوظائف الحكومية في الدول النامية تكون منخفضة، وبالتالي لن تكون جاذبة للأكفاء للعمل بها، كما أن هذه الرواتب المنخفضة

$$
\text { تؤدي إلى انحرافات إدارية ومالية. (النجار والمغربي، } 149 \text { - 154) }
$$

العوامل الاجتماعية

ويقصد بها تلك الأمور المتصلة باللغة والقيم والتقاليد والعادات والظروف السائدة في أي مجتمع، وهي من الأمور التي تتعكس على الإدارة العامة وتؤثر فيها، وفي فاعليتها. فظواهر مثل المحسوبية أو الرشوة أو الفساد الإداري إذا لم تكن مستهجنة من المجتمع وقيمه وعاداته وتقاليده وأعرافه سوف التهن تمتد وتستشري في جسد الجهاز الإداري ومنظمات الإدارة العامة ومن ثم إلى القرارات الهامة التي تتخذها الإدارة.

وعندما تسود قيم كالقناعة والرضاء بالأمر الواقع والكسل والقتوع بما هو واقع ينعكس ذلك على قدرة الأفراد في تحقيق أهداف التتمية، ومن ثم يؤثر على قدرة أجهزة الإدارة العامة في تحقيق تلك الأهداف. لكن في بعض المجتمعات المتقدمة يكون طموح الأفراد مرتفع ورغبتهم في مستوي حياة كريمة عالية ومن ثم يشكلون قيم إيجابية مؤثرة على قدرة الحكومة وأجهزتها في تحقيق التنمية المنشودة. كما تؤثر العلاقات القبلية والعائلية على المنظمات العامة وأداء أجهزتها، ففي ظل العلاقات القبلية والعائلية تكون الوظائف على أساس درجة القرابة والعوامل الثخصية وليس على أساس الكفاءة والجدارة والموضوعية والمعايير المحايدة، وهو ما يؤثر بالسلب على أداء الإدارة، ويؤدي لانتشار المحسوبية والمحاباة. وكذلك الأمر بالنسبة إذا كان المجتمع مقسم إلى طبقات أو فيه تمييز من نوع ما، فسيؤدي ذلك إلى منح فئات ما مميزات معينة لا تمنح لآخرين. (أفندي، 70- 71:

$$
\text { 2002)، (النجار والمغربي، } 154 \text { - 160). }
$$




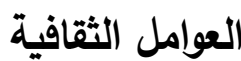

"يتأثر النظام الإداري بمدي انتشار الثقافة السائدة في المجتمع، فكلما ارتفع مستوي التعليم ارتفع مستوي الثقافة. وبالتالي اتسع الهجال لاختيار أصلح العناصر البشرية لتولي الوظائف العامة في الدولة. إذ يعد العنصر البشري المثقف والمؤهل والمدرب من العوامل المهمة المؤثرة في قدرة الجهاز الإداري على القيام بالأعباء الملقاة على عاتقه وأهمها تحقيق التتمية الاقتصادية بكفاية عالية وبأقل

$$
\text { تكلفة" (محمود، 30: 1997). }
$$

كما تؤثر بعض الجوانب الثقافية والتعليمية في نمط الأداء وسلوكيات الأجهزة الحكومية في المجتمعات. حيث إن ارتفاع مستوي التعليم والثقافة يؤثر على التوجهات الفكرية للأفراد ومدي لهي مشاركتهم في الديموقراطية والرقابة على أعمال الحكومة، وبالتالي لا تتفرد الحكومة بالسلطة. كما أن انخفاض مستوي الوعي الثقافي والتعليمي يؤثر على الإدارة العامة حيث ستكون هناك صعوبة في التطوير والتحديث المرتبط بالتعليم ومستوياته العالية. العوامل التاريخية

إن الأنظمة السياسية والإدارية والاقتصادية و...الخ أُفرزت نتيجة تراكم خبرات علمية وعملية وحضارية وتاريخية داخلية وخارجية متتابعة أثرت في تلك الأنظمة. فمثلا مصر دولة مركزية منذ القدم بسبب طبيعة مجتمعها الزراعي مما أدى إلى ضرورة وجود بيروقراطية ضخمة ومركزية تعتمد عليها السلطة لتسيير أمورها. وثم ورثت السلطة ميراث حضاري وتاريخي ثقيل تتعامل هي معه. كما مرت المنطقة العربية مثلا بحقبة الاستعمار وما تركه من آثار على الدولة وأجهزتها الإدارية سواء من ناحية التركيز على بعض الجوانب وإهمال أخري، أو إضعاف قطاعات وتقوية قطاعات، أو بعض القوانين التي نشأت في حقبة زمنية ما ولا تزال آثارها سارية وهكذا" (أفندي، 71 - 72:

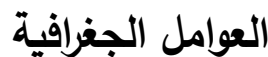

توثر العوامل الجغرافية التي تثمل الموقع والحدود والمناخ والمساحة والتضاريس والسكان والتربة والثروات النباتية والحيوانية والمعدنية وغير ذلك على طابع الحياة الثقافية والاجتماعية والاقتصادية ومن ثم على الإدارة. فحجم الدولة مثلا واتساعها أو صغرها يؤثر في شكل الإدارة العامة، فقد يستلزم الأخذ بنظام اللامركزية الإدارية إذا كانت الدولة مترامية الأطراف. كما يؤثر أيضا في كمية الموارد الطبيعية المتاحة ومدي حاجة الدولة إلى نظام إداري قوي أو مركزي أو حرفي لاستخراج 
تلك الموارد وتوزيعها بشكل عادل بين المواطنين. وزيادة السكان مثلا يكون عاملاً في انتقال المواطنين وتكسهم في مكان معين تتوافر فيه الإمكانيات والخذمات مما يزيد الضغط على الإدارة العامة ويدفعها لتوفير احتياجاتهم بكفاءة وفعالية. كما تؤثر الطبيعة الجغرافية على سلوكيات الأفراد وأخلاقهم، بل تؤثر على الإنتاج ففي البلاد الحارة يقل الإنتاج، ويزيد في البلاد الباردة أو معتدلة الحرارة. كما أن طبيعة الثروات الطبيعية في البلاد تحدد نوع الأعمال والمشروعات المرتبطة بها. كل هذه الظروف الجغرافية تؤثر في بناء النظام الإداري وقدراته" (محمود، 26 - 28: 1997). فعلى سبيل المثال يري د. جمال حمدان أن أحد أسباب تضخم الجهاز الإداري الدصري "خلفية

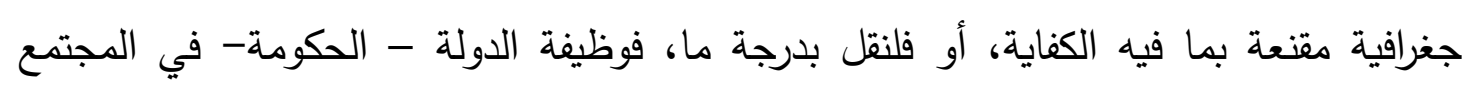
الهيدرولوجي المنشغل بالزراعة والري أضخم بلا ريب من الوظيفة المألوفة للدولة. فكعامل جغرافي

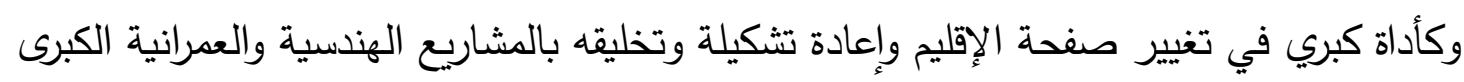

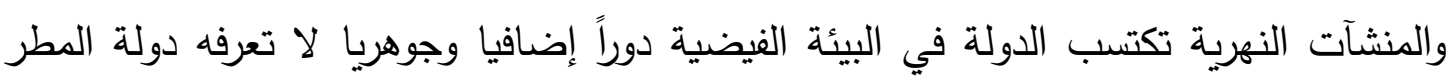
العادية، ثم إلى جانب هذا الجهاز الفني الضخم بمعناه الهندي المباشر، لابد من جيش من لهن الخبراء والمشرفين على عملية الزراعة التي لا يمكن أن تتم على أسس فردية عشوائية. حول هذه النواه الصلبة من التكنوقراطيين تتري بالضرورة حلقات كثيفة من البيروقراطيين، تبدأ بالجهاز المالي

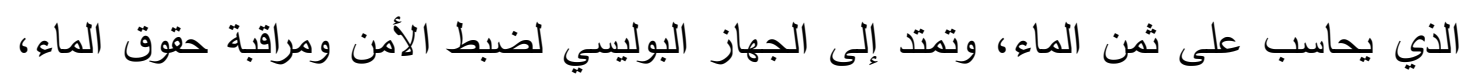

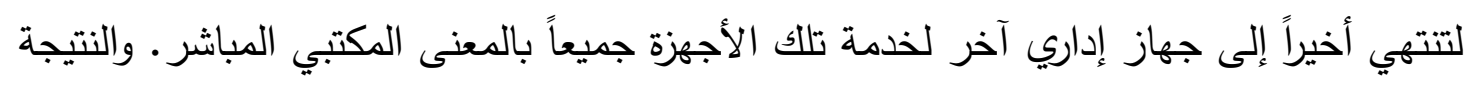

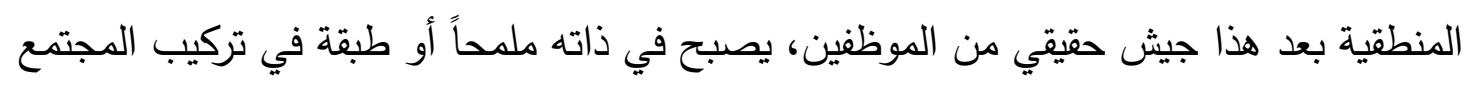

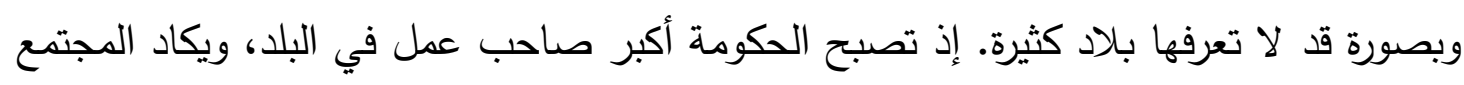
يتحول إلى مجتمع حكومي صرف. (حمدان، 274 - 275: 1984).

العوامل التكنولوجية

تؤثر التكنولوجيا تأثيراً كبيراً على الإدارة العامة وأجهزتها وتتظيماتها ومكوناتها وعملياتها والعاملين فيها. فالتكنولوجيا تتسم بسرعة التغيير الكبيرة في المعدات والبرامج المستخدمة وسرعة الانتثار في لئي

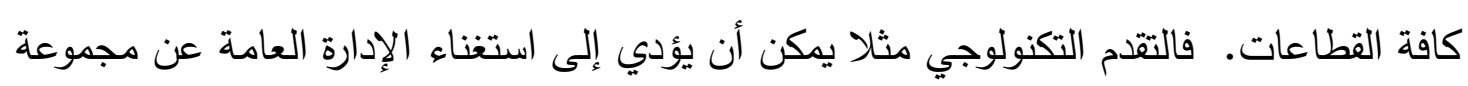
من العاملين نظراً لإحلال التكنولوجيا محل الإنسان في بعض الأحيان، بل تطوير بعض الأساليب

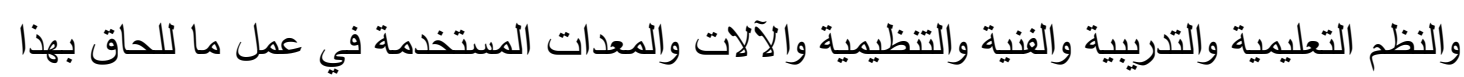
التطوير. 
كذلك أدت التكنولوجيا إلى التغير في نوعية النشاط الاقتصاد، من اقتصاد المعلومات إلى اقتصاد

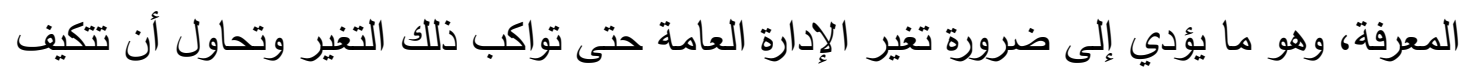

$$
\text { مع هذه البيئة الجديدة (النجار والمغربي، } 160 \text { - 164). }
$$

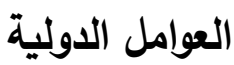

تشمل العوامل الدولية عدداً من الظواهر المؤثرة على الإدارة العامة مثل: المنظمات والشركات الدولية، والتكتلات الدولية. وقد زاد تأثير تلك العوامل بعد تتامي ظاهرة العولمة. فالمنظمات الدولية تؤثر في قرارات السياسة والإدارة معاً، فهذه المنظمات أو الشركات العملاقة متعددة الجنسيات مثلا تغزو الأسواق المحلية، وتحاول السيطرة على السوق التجارية للدولة، ومن ثم فهي منافس قوي للمنظمات العامة في أي دولة ولمنتجاتها، وبالتالي على الإدارة العامة أن تتكيف وتطور من نفسها لتواكب هذ التنافس وإلا فإنها ستكون في موقف ضعيف غير قادر على

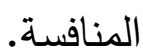

كذلك فإن التكتلات الدولية تفرض التزامات على الدولة الوطنية وأجهزتها الإدارية من إعفاءات جمركية أو ضريبية أو تسهيلات إدارية وتبسيط لعدد من الإجراءات التي كانت متبعة، أو سعي تلك الأجهزة الإدارية بنفسها إلى المشاركة والمساهمة، وكل ذلك يؤثر على الإدارة العامة سواء بالسلب أو بالإيجاب (النجار والمغربي، 164 - 168). ثالثًا- أثر المنهج الإيكولوجي على دراسة الإدارة العامة تُعد المناهج العلمية أحد أهم العوامل المساعدة في إيجاد أو استكثاف أساليب واستراتيجيات فهم الظاهرة محل البحث. ومن أبرز تلك المناهج - حسب ما تم تناوله في العديد من الأدبيات التي ناقثت مناهج وأساليب واستراتيجيات البحث المقارن - المنهج الإيكولوجي. وسنتتاول في هذا الإطار دور المنهج الإيكولوجي وأثره على مفهوم البيروقراطية كوحدة للتحليل الدقارن، بالاستناد إلى أهم مدرستين سعتا للتتسير باستخدام أسلوب المقارنة. وتسعى الدارسة لإبراز ذلك من خلاد ثلاث عناصر هي: وحدة التحليل، والفرضيات والمقولات، وأهم رواد كل مدرسة. وهي كالتالي:

\section{1- المدرسة التقليدية}

من أنصار هذه الددرسة رجز Riggs، وهيدي Heday. وقد اتخذت من البيروقراطية وحدة للتحليل، واعتبرت البيروقراطية - وفقاً لهذه المدرسة - بأنها متغير تابع. وتعتمد هذه المدرسة التقليدية على استراتيجية Outside in Process. وتقوم الفرضية الأساسية لها باعتبار 
البيروقراطية نتاج عوامل ومتغيرات في محيط عمل الإدارة، وأن التغيير لا يأتي إلا بالتحكم في متغيرات تلك البيئة. فالإنسان ابن بيئته والمؤسسات لا تعمل في فراغ وإنما في محيط فاعل ومؤثر. وتستند مقولاتها الأساسية على أن المدرسة البيروقراطية القومية أو الوطنية نظام فرعي داخل السياق المجتمعي الأكبر بما يشمله من نظم سياسية واقتصادية واجتماعية وتكنولوجية وإعلامية و ..الخ. إضافة إلى أن البيروقراطية هي نتاج التفاعل بين عوامل ومتغيرات البيئة المحيطة، ومعني ذلك أن النظام الإداري يعكس خصائص البيئة الموجودة بها. أي أن هذه الددرسة تتطلق من الكل إنل

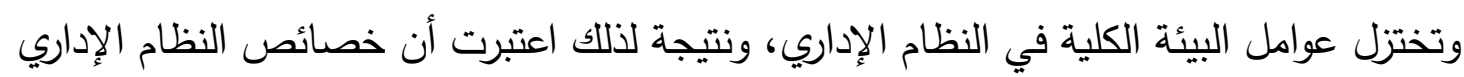
يمكن فهمه وتفسيره من خلال دراسة النظام الاجتماعي السائد. وهكذا تتبلور معالم هذه المدرسة في أن فهم البيئة التي تعمل في إطارها وحدة التحليل "البيروقراطية" مفتاح أساسي في تفسير وفهم طريقة عمل هذه الوحدات، ومن هنا يأتي تأكيد الباحثين على أهمية فهم المتغيرات البيئية من ثقافة واقتصاد وتكنولوجيا وسياسة والتي تثتغل في إطارها المنظمة

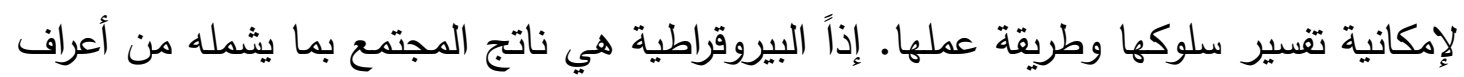

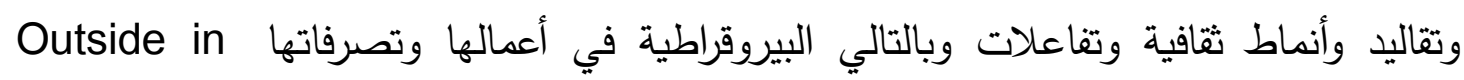
Process (2) يحاول توضيح الفكرة.

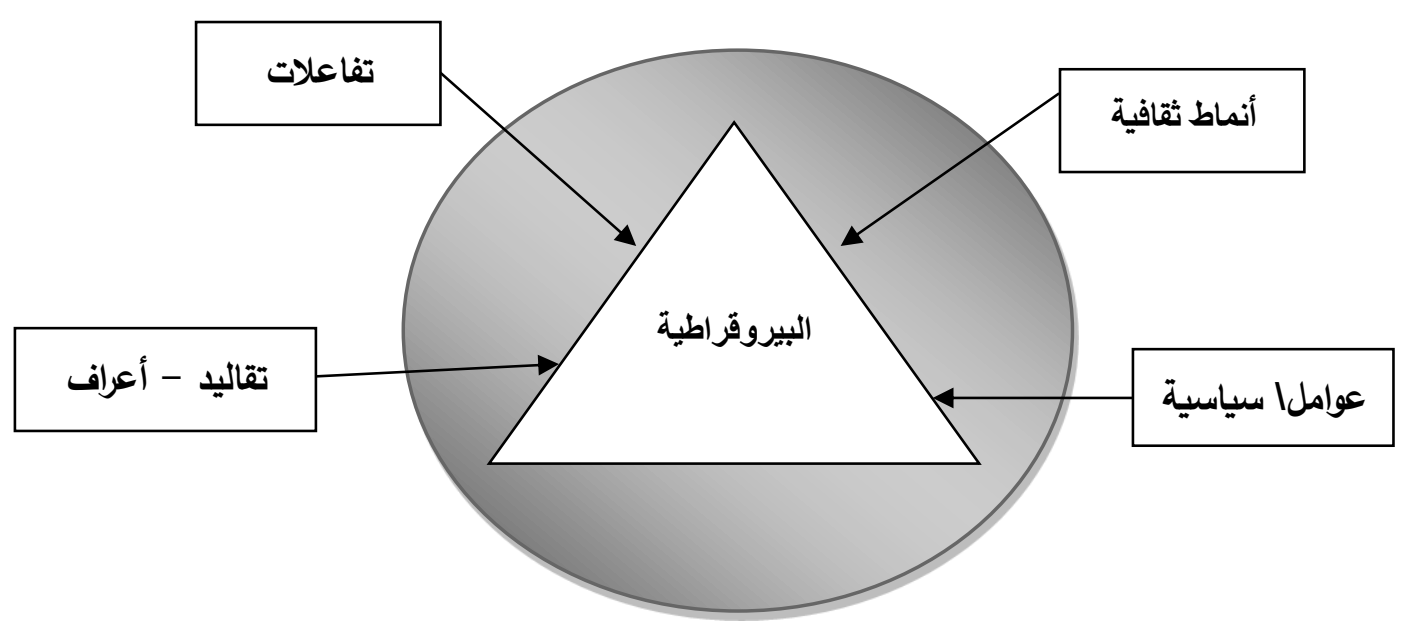

شكل (2): تأثير البيئة المحيطة على البيروقراطية 
وقد هيمن هذا الاتجاه على العديد من الدراسات التي أجريت في تلك الفترة والتي كانت عابرة

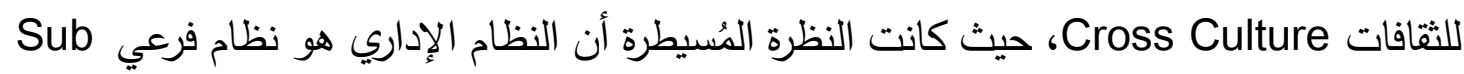
System في النظام السياسي وبالأخص نظام الحكم (علاقة السلطات الثلاث). وفي النهاية فإن نظم الحكم تؤثر بشكل مباشر أو غير مباشر على الأنشطة والعمليات وأساليب التنفيذ والمراجعة في عمل الإدارة. وبناء علي ما سبق ينطلق أنصار هذا الرأي من مقولة مفادها أنه لكي يتغير النظام الإداري لابد من تغيير النظام السياسي والنظم المحيطة الاجتماعية والثقافية والاقتصادية والتكنولوجية ..الخ. ولا يتأتى التغيير إلا من تغيّر الكليات المحيطة أو البيئات المحيطة، وهي من لإنيل الأمور التي غابت عن هذه المدرسة ذلك أن التمكك بالآليات يؤدي إلى الجمود. وقد ثار تساؤلين على دقولات هذه المدرسة، الأول يتعلق بكيفية تغيير البيئة الخارجية لتكون ملائمة لإجراء التغيير

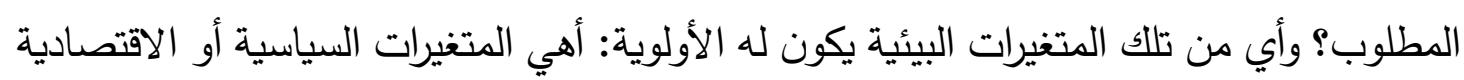

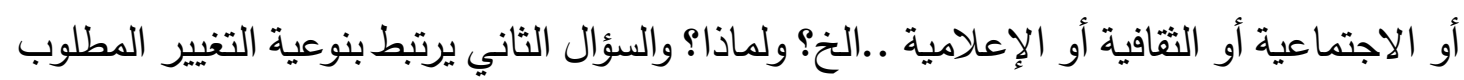
إحداثه، وما هي مواصفات تلك النظم البيئية التي يمكن أن تتسجم مع البيروقراطية وتسعى في البعاي تحديثها وتطويرها؟ 2- المدرسة الحديثة

وعلي عكس المدرسة الأولى ينطلق أنصار هذه المدرسة من فرضية فحواها أن الإدارة هي نظام

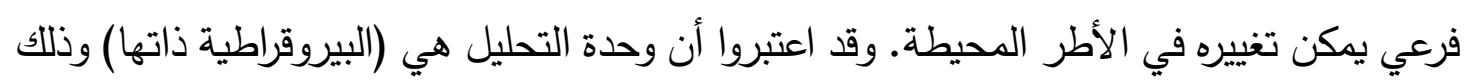

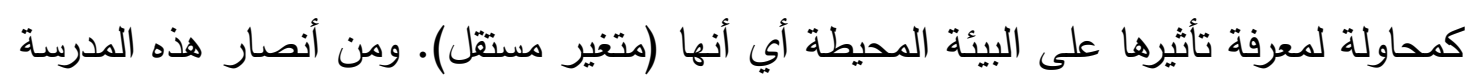
ج.بيترز - روكمان - بوتان، واعتمدت هذه الدرسة استراتيجية Inside Out Process. وتتلخص آراء ومقولات هذه المدرسة في أن الإدارة مثل أي نظام فرعي يمكن تغييره وتبديله وتطويره والسيطرة عليه لو تغيرت نظم التدريب والتعيين والتمويل..الخ وبالتالي فسوف يتغير النظام الكلي ويحاول الثكل (3) تبيين الفكرة. 


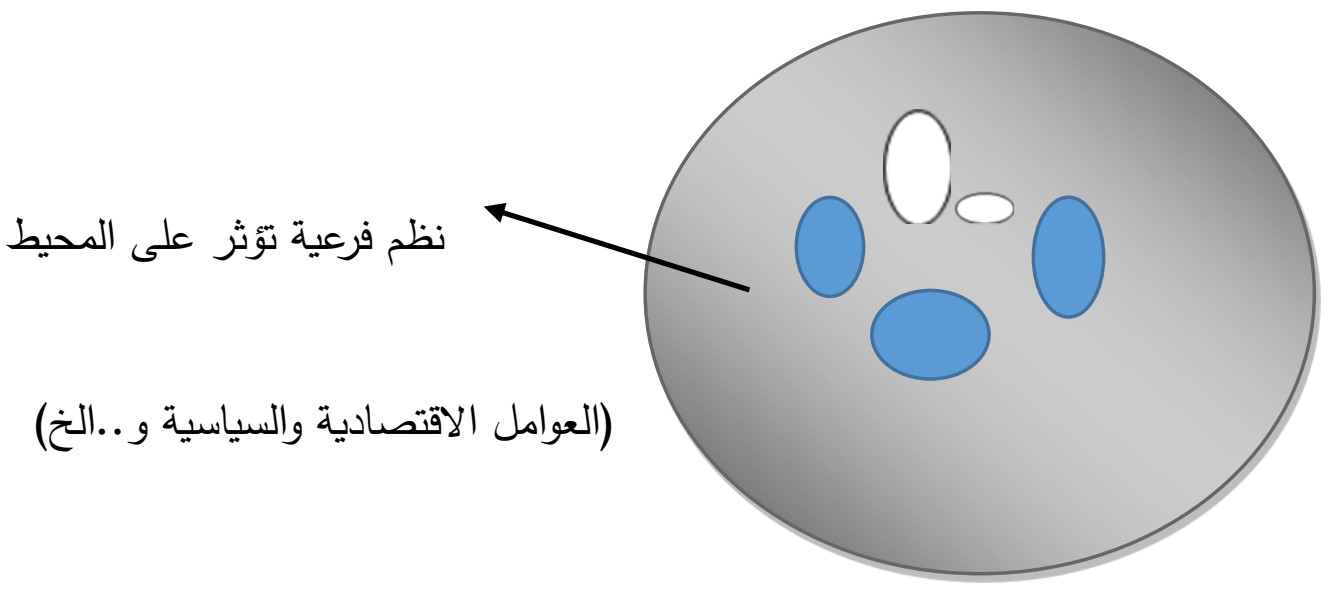

شكل (3): تأثير البيروقراطية على البيئة المحيطة

ورأي أنصار هذه المدرسة أن موقف المدرسة التقليدية لا تدعو إلى التطوير لأنها تتمسك بكليات جامدة باعتبار أن النظام الثقافي يتكون عبر سنوات طويلة. ومن ثم ذهبوا إلى إمكانية التحكم في تلك النظم من خلال السيطرة على البيروقراطية باعتبارها أداة للنظم المحيطة. فلو تم تغيير نظم اختيار القيادات والتعيين والتمويل والتدريب واللوائح والقوانين المنظمة للعمل والعاملين مثلا نستطيع أن نُغير المجتمع وفي عبارة أخري فإن البيروقراطية تعتبر أداة للتغيير وهو ما أشار إليه "بيترز". لقد أطلق أنصار هذه المدرسة على أنفسهم اسم الإصلاحيين أو التجريبيون لأن هدفهم تمثل في الوصول إلى علم تجريبي. وتتشد هذه المدرسة إدارة عامة تقوم على أساس المنهج العلمي التجريبي من خلال إخضاع المتغيرات البيئية تحت السيطرة، ومن وجهة نظر العلم هناك ضرورة لوجود Welch and،41998) متغيرات يسهل التحكم فيها، أما الوسيلة فهي دراسة النظم المتشابهة Wong ومن الانتقادات التي صوبت لهذه المدرسة هو تجاهلها للتأثيرات البيئية المحيطة بالمنظمات والبيروقراطية وأثرها في سلوكيات الأفراد. فالدول النامية تعاني من جمود إن لم يكن ضعف الحراك الطبقي فيها وتدني مستويات التعليم وتآكل الطبقات الوسطي مما ينعكس على عمليات التغيير والتحول المنشود. ومن ثم فإن ما أهلته هذه المدرسة هو أثر البيئة الخارجية بتغيراتها المختلفة على كل من الأفراد أولاً وعلى منظماتهم التي يعملون فيها ثانياً. والشكل (3) السابق يحاول توضيح الفكرة.

ويبقي القول بوجود اتفاق بين المدرستين التقليدية والحديثة على اعتبار البيروقراطية كوحدة للتحليل غير أنهم اختلفوا في كونها متغيراً تابعاً أو مستقلاً، ومَرَدُ ذلك يعود للفرضيات والمقولات الأساسية 
التي انطلقت منها كل مدرسة. ويبين جدول رقم (2) أهم الاختلافات بين المدرسة التقليدية والمدرسة الحديثة.

جدول (2): أهم الاختلافات بين المدرسة التقليدية والمدرسة الحديثة

\begin{tabular}{|c|c|c|}
\hline المدرسة الحديثة / الإصلاحية & المدرسة التقليدية & \\
\hline 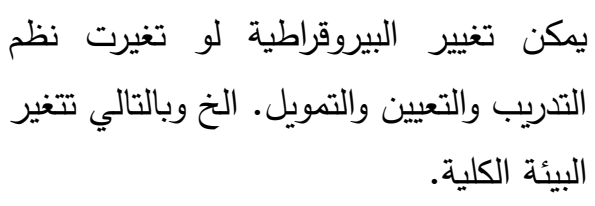 & متغل البيروقراطية نتاج عوامل ومتغيرات في محيط الإدارة. التغيير لأئ إلا بالتي & الفرضية \\
\hline Inside Out Process & Outside in Process & الاستراتيجية \\
\hline البيروقراطية - وهي متغير مستقل & البيروقراطية - وهي متغير تابع & وحدة التحليل \\
\hline ج.بيترز - روكمان - بوتان & فريد رجز Riggs، وفيريل هيدي Heday & أنصارها \\
\hline أهملت دور البيئة الخارجية وآثارها ومتغيراتها & الإجراء التغيير التيير البيئة الخارجية لتكون ملائمة & النقا الموجه \\
\hline
\end{tabular}

المصدر: الجدول من إعداد الباحث

\section{رابعًا- رؤية تقييمية للمدخل الإيكولوجي - البيئي}

على الرغم من أهمية المدخل الإيكولوجي في دراسة الإدارة العامة وما كثفه من جوانب كثيرة متداخلة ومترابطة تؤثر في الإدارة وتتأثر بها إلا أنه ووجه بانتقادات، يمكن عرضها كالتالى: 1- ليست كل العوامل البيئية ايجابية أو سلبية حيث "إن المبالغة في المنهج الثقافي والبيئي قد تؤدي إلى النظر إلى الثقافة كسبب للإخفاق وحده، مع استبعاد الوجه الآخر لهذه المقولة وهو أن الثقافة قد تكون هي المدخل إلى النجاح أيضا. أليس من الجدير بالتأمل ظاهرة أن الدولتين الثرقيتين الوحيدتين اللتين تمكنتا من عبور حاجز التخلف والانطلاق نحو التنمية الحقيقية المعتمدة على النفس هما اليابان والصين، وهما نموذجان يعبران - رغم تباينهما الإيديولوجي - عن الأصالة الثقافية ومحاولة استلهام التراث في سبل التتمية والتقدم. ثم نقارن هذين النموذجين بحالة تركيا والفلبين مثلا حيث أدى التركيز على محاكاة

$$
\text { الغرب إلى الفرنجة دون أن يؤدي إلى تقدم (أفندي، 73: 2002). }
$$

2- الأهم في المنهج الإيكولوجي هو إيضاح العلاقة بينه وبين السلوك الإداري ف"مجرد سرد الأحوال والعوامل والظروف البيئية لا يعد منهجاً إيكولوجياً سليماً لدراسة الإدارة العامة، 
إنما يحتم الاتجاه العلمي إيضاح الارتباط والتفاعل بين المتغيرات المؤثرة في بيئة بذاتها

$$
\text { وبين السلوك الإداري في هذه البيئة".(أفندي، 73: 2002). }
$$

3- العوامل البيئية ليست حتمية "من حيث أنها تشكل السلوك الإداري بصورة لا يمكن تغييرها،

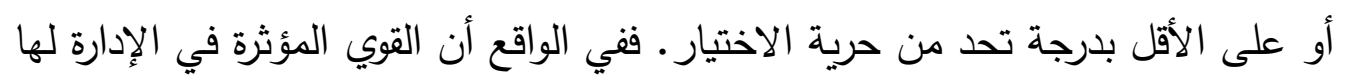

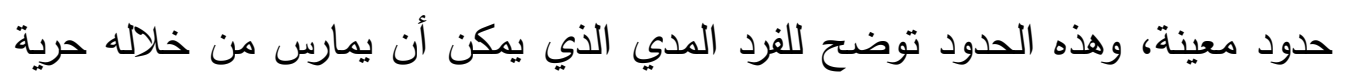
الاختيار ، وهكذا يكون للبحث العلمي وللدور الذي يؤديه القادة ولبرامج التدريب والتتمية آثارها الملموسة في مواجهة العوامل البيئية المؤثرة في تقدم وتطور الإدارة العامة"(أفندي، ولئ (2002:74

4- هناك صعوبة في دراسة المنهج البيئي بالكامل "فتحليل الظروف البيئية بأبعادها المختلفة السياسية والتاريخية والاجتماعية والاقتصادية والثقافية بالإضافة إلى العادات والتقاليد يعني

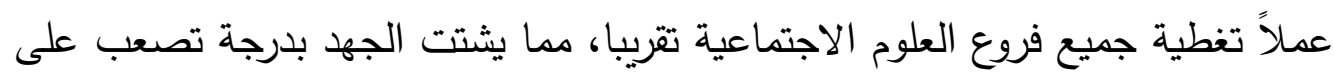
الكثير من الباحثين. يؤكد ذلك أن العوامل البيئية المشار إليها تختلف من مجتمع لآخر بل ومن وقت لآخر في ذات المجتمع"(أفندي، 74: 2002).. كما أن بعض العوامل متغيرة ومتقبلة بدرجة سريعة وبالتالي يصبح محاولة دراستها أمراً عسيراً. 5- "أن المدرسة البيئية في الإدارة ذات قيمة كبيرة إذا أخذت بمقدار فاستخدمناها كمنهج في لئه الوصف والتحليل يعيننا على فهم العوامل الثقافية والاجتماعية التي يمكن استخدامها

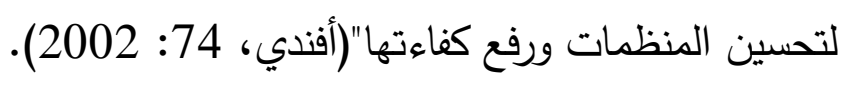

6- من الهام التخفيف من غلواء المنهج البيئي وذلك "بتوليفها مع بعض مظاهر المنهج

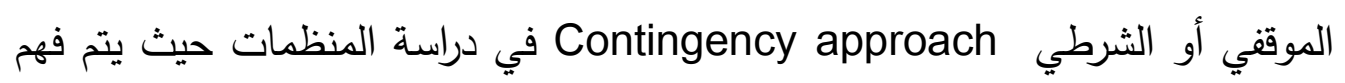
الأنثطة التتظيمية باعتبارها خاضعة لتأثير الموقف التتظيمي وليس لتأثير البيئة الثقافية

$$
\text { فحسب"(أفندي، 74: 2002). }
$$

خامسًا - المنهج المقارن في دراسة الإدارة العامة: تعريفه وأهدافه تعتبر الإدارة المقارنة "امتداد لتطبيق فكرة المدخل الإيكولوجي في دراسة الإدارة العامة على أساس مقارن، حيث يمتد البحث إلى أنماط الإدارة في الدول المختلفة، وإبراز السمات والمميزات التي تتمتع بها والعوامل المؤثرة فيها بكل دولة أو مجموعة دول" (أفندي، 2012). 
ويُعرف المنهج على أنه "طريقة تؤدي إلى الكثف عن الحقيقة في إطار العلوم من خلال مجموعة من القواعد التي تهيمن على سير العقل كي يصل إلى النتيجة المطلوبة، إنه أسلوب في التفكير المنظم" (أفندي، 132: 2012).

ويُعرف بأنه "طريقة البحث أي الطريقة أو المسلك الذي يتخذه الباحث في المراحل المختلفة لعملية البحث، وتوسع بعض التعريفات من مفهوم المنهج ليشمل القواعد والأسس العلمية في البحث. لكن يمكن القول بأنه مجموعة الإجراءات الذهنية التي يتمثلها الباحث مقدماً لعملية المعرفة التي سيقبل عليها من أجل التوصل إلى حقيقة المادة التي يستهدفها. (رشاد، 37: 2004). " والمنهج هو أحدد مكونات العلم وليس مرادفاً، فهو إجراءات وطرق الوصول إلى المعرفة التي تتضمن قواعد وخطوات الإجابة على أسئلة البحث واختبار فرضياته". (عارف، 73 - 74: $\cdot(1998$

وتُعرف المقارنة بأنها "دراسة ظواهر متشابهة متتاظرة في مجتمعات مختلفة، أو هي التحليل المنظم للاختلافات في موضوع أو أكثر عبر مجتمعين أو أكثر"(عارف، 81 - 82: 1998). والمقارنة بمعناها العام تعني "الوقوف على أوجه الاختلاف والاتفاق بين الظواهر، أي أنها مطلب رئيسي في التحليل العلمي لأي ظاهرة، والمقارنة متضمنة بطبيعتها في أية محاولة للتحقيق من صحة الفروض، ولتحقيق هدف العلم في دراسة التباين والاختلاف، أو التماثل والتشابه بين الظواهر الواقعية، وتحديد الثروط والظروف التي تقف وراء هذا الاختلاف والاتفاق. وهي ضرورة منهجية يتطلبها التعميم، كما أن العلاقات السببية يمكن اكتشافها من خلال ذلك التنوع في الظروف التي تتيحها المقارنة" (رشاد، 241: 2004). وهناك من يفرق بين مفاهيم: الإدارة المقارنة، والدراسة المقارنة للإدارة، والمنهج المقارن، والتحليل المقارن، والمدخل المقارن أو المدخل البيئي المقارن 1 (رسلان، 297: 1990).

1 يري نبيل رسلان أن مصطلح الإدارة العامة المقارنة يعني "أن الإدارة المقارنة فرع من علم الإدارة العامة يتناول دراسات في

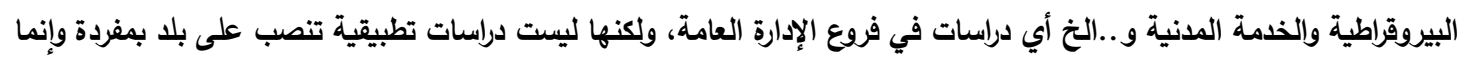

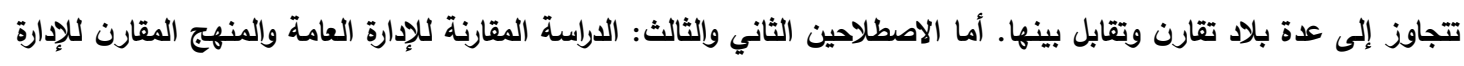

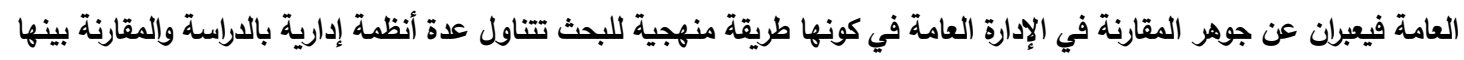

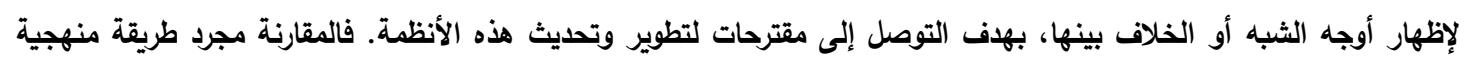

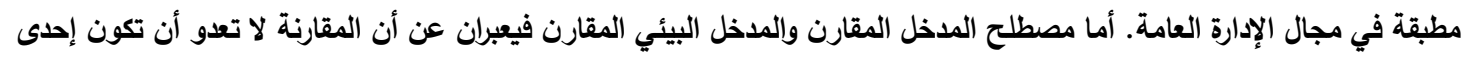
المداخل المستخدمة في دراسة الإدارة العامة. 
وهناك من يعرف الإدارة العامة المقارنة بأنها "علم مناهج البحث المقارن في نطاق الإدارة العامة حيث أنها تعالج قواعد الطريقة المنهجية المقارنة مطبقة على أنظمة الإدارة العامة" (رسلان، 299:

1990). أو "هي الحلقة المتقدمة من حلقات دراسة الإدارة العامة. أو هي الدراسة المقارنة للمؤسسات، والعمليات، والسلوك عبر ثقافات متعددة ومجتمعات مختلفة. أي دراسة الإدارة العامة أو أحد جوانب الإدارة العامة في إطار بيئات متعددة." (درويش، 2014). أهداف التحليل المقارن يكمن هدف "الدراسة المقارنة للإدارة العامة في إطار دراسة ظواهر ومشكلات الحكومات المقارنة... في التعرف على هذه المشكلات أو الظواهر وتحديد أوجه التشابه وأوجه الاختلاف واقتراح الحلول والحلول البديلة لحل المشكلة موضوع المقارنة"(محمود، 40: 1997)، ويمكن تقسيم أهداف المقارنة إلى أهداف علمية مثل: زيادة وتعميق المعرفة النظريـة في الإدارة العامة وتكوين افتراضات ومفاهيم حول الإدارة تتعدي وتتجاوز الحدود لكل بلد. وأهداف أخرى عملية مثل: تطوير الأنظمة الإدارية لجعلها أكثر كفاية وفعالية والتعرف على حلول أفضل لعديد من المشكلات الإدارية (رسلان، 299 $\cdot(1990 ، 300-$ ويري د. عطية حسين أفندي أن التحليل المقارن يرمي إلى تحقيق عدة أهداف أهمها: • "إثراء المعرفة النظرية والواقعية بالأنظمة والأنساق المختلفة. • تقييم الخبرات والمؤسسات والتفاعلات وأنماط السلوك. • التنبؤ بالأحداث والاتجاهات والنتائج.

• تحديد أي من المنظمات أكثر كفاءة، وطرح حلول أفضل لعدد من المشكلات" (أفندي،

$$
.(2002: 136-135
$$

\section{سادسًا- تطور الاراسة المقارنة للإدارة العامة: الثابت والمتغير}

يمكن للمتتبع للدراسات المقارنة في الإدارة العامة أن يلحظ مرورها بثلاث مراحل. ففي الأولي اقتصرت على مجموعة من المداخل التقليدية الوصفية، وفي الثانية شهدت تطورات نظرية وعملية، وفي الثالثة حاولت تقديم إسهام نظري مقارن. يعرضها الباحث بإيجاز شديد، كالتالى: أ- تطور مداخل دراسة الإدارة العامة المقارنة المدخل الأول: المدخل القانوني، الدستوري، التاريخي: ظهر في نهاية القرن التاسع عشر وبداية القرن العشرين، وركز هذا المدخل على الحقوق الدستورية والقانونية للحكومة ووظائفها وسلطاتها 
والواجبات المفروضة عليها إلى جانب الاهتمام بالأوضاع الإدارية والعلاقات بين السلطات المركزية والحكومات والهيئات المحلية. وكانت الدراسات الإدارية مرتبطة بالقانون الإداري. لكن أبرز

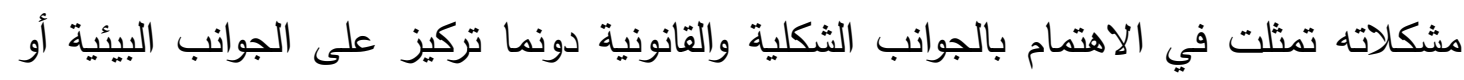
العمليات الإدارية.

المدخل الثاني: المدخل التتظيمي الوصفي: ظهر في بداية القرن العشرين، ويعتبر أهم علماء هذا المدخل ليونارد هوايت Leonard White، واهتم هذا الدخخل بإبراز مقومات الإدارة في أربعة جوانب أساسية، وهي (التنظيم - القوي البشرية - التمويل - التشريع والضوابط القانونية)، لكن

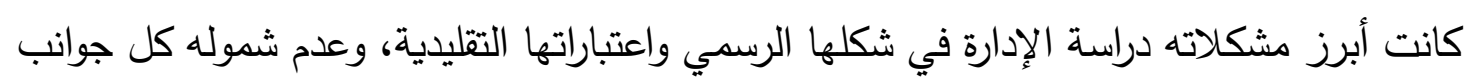
العملية الإدارية، وإهماله دراسة المتغيرات البيئية. المدخل الثالث: المدخل الاجتماعي النفسي: Socio-Psychological Approach، ركز على الجوانب السلوكية في الإدارة، حاول فهم العملية الإدارية في ظل العوامل السلوكية، وقد اهتم بدراسة وفهم المواقف الإدارية على عكس تركيز المداخل السابقة على ما يجب أن تكون عليه الإدارة،

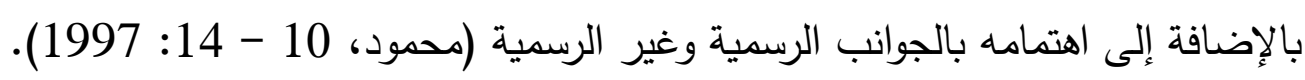
والمدخل الرابع، وهو المدخل الإيكولوجي والذي سبق عرضه في بداية البحث. ب-تظور الدراسات والبحوث في إطار دراسة الإدارة العامة المقارنة ساعد المنهج المقارن بشكل كبير في تطور علم السياسة فقد استخدمتها العديد من الدول قديما، ومن أهمها اليونان من أجل المقارنة بين الأنظمة السياسية لمدنها وذلك لتبني الأنظمة المثلي. فمثلا قام أرسطو بمقارنة 158 دستور من دساتير هذه المدن في كتابه "السياسة" واعتمد على مبدأ الضرورة القائم على أساس أن لكل دولة خصوصياتها. ثم جاء أفلاطون واعتني بالدراسة المقارنة للنظم السياسية، ثم توالى عدد من المفكرين والكتاب الذي اعتتوا بالدراسات المقارنة مثل: ابن خلدون عندما تحدث عن أطوار الدولة وأعمارها، والفارابي والدولة الفاضلة والدولة الثريرة، ثم

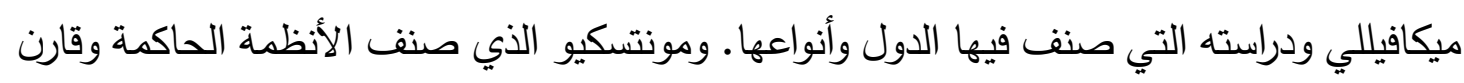
بينها. ثم جاء دور كايم وألف كتابه " قواعد المنهج في علم الاجتماع" (كايم، 1988). ولا غرو

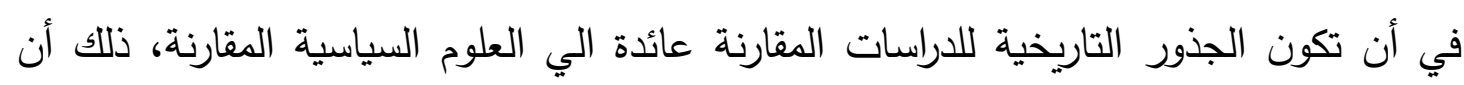
الوصل والاتصال بين العلوم السياسية والإدارة العامة استمر لقرون قبل أن يستقل علم الإدارة العامة في منتصف القرن العشرين ويصبح علماً قائماً بذاته. 
غير أن حجر الأساس أو نقطة الانطلاق للدراسات المقارنة في مجال الإدارة كانت مقالة ودور ويلسون حول "دراسة الإدارة العامة" عام 1887 والذي اعتمد على الخبرات الأوروبية لتحسين الإدارة في الولايات المتحدة الأمريكية، ودراسة روبرت دال حول "علم الإدارة العامة" عام 1947،

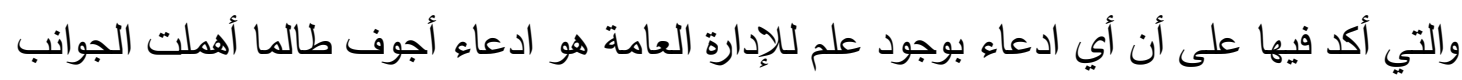

$$
\text { المقارنة للإدارة العامة (هيدي، 13). }
$$

وهنالك مجموعة من العوامل التي ساعدت على ظهور حقل الإدارة العامة المقارنة: هالحرب العالمية الثانية وتزايد سلطات الإدارة في ظل ظروف الحرب والتي اتسدت بالتشابه

مما دفع إلى نوع من الدراسات المقارنة.

ظهور دول تعمل على عكس القيم الغربية (اليابان، الاتحاد السوفيتي السابق، الصين). ظهور الدول حديثة الاستقلال وما تبعها من مشكلات إدارية مختلفة أوضحت عدم قابلية القواعد الغربية للتطبيق. دور المنظمات العالمية والأمم المتحدة وبرامج المعونة، الأمر الذي فرض ضرورة التوصل لمبادئ إدارية عالمية من أجل تعظيم الاستفادة من برامج المعونة الدولية. تطور العلوم الطبيعية وما صاحبه من ضرورة تطور العلوم الإدارية لتعظيم الاستفادة من التطور السابق، وذلك من خلال البحث عن حلول مقارنة للمشكلات الإدارية. تطور الفكر السلوكي من خلال دراسات هاربرت سايمون حول أهمية دراسة السلوك البشري بشكل مقارن. التقدم العلمي والتطور التقني والبحث عن الدراسات المقارنة لمواجهة المشكلات الناجمة

$$
\text { عن هذا التحول (محمود، } 54 \text { - 73: 1997). }
$$

واستتبع ذلك تبلور عدد من التطورات البحثية في مجال الدراسات للإدارة العامة المقارنة، تمثلت في أربع أطوار، ففي الطور الأول وجدت الدراسات التي قامت بوصف نظام الإدارة العامة

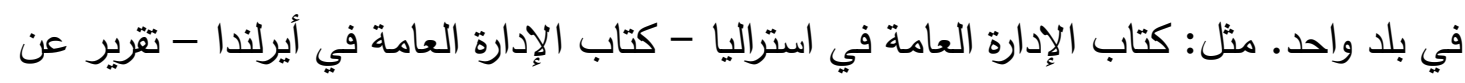
الإدارة في لبنان أو عن التتظيم الحكومي في الهند. وفي الطور الثاني جاءت الدراسات التي تعالج

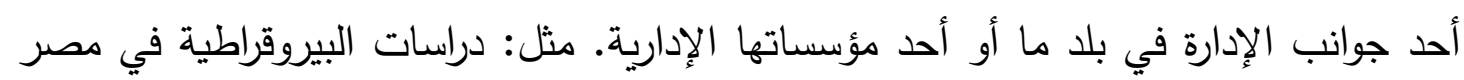
والفلبين وكندا وسويسرا ووظيفة الرياسة في الولايات المتحدة - الوظيفة العامة في فرنسا- تدريب العاملين في تركيا، ونظم دراسة الإدارة العامة في باكستان. وفي الطور الثالث اشتهرت الدراسات 
التي تتناول أحد مقومات الإدارة أو أحد موضوعاتها في أكثر من دولة، مثل: دراسة نظم العاملين في دول أمريكا اللاتينية - دراسة البيروقراطية في بعض دول غرب أوروبا - دراسة القطاع العام في فرنسا وإيطاليا وبولندا- دراسة الإدارة القومية والمنظمات الدولية في أربع عشرة دولة، دراسات البنك الدولي وتقارير الأمم المتحدة. وفي الطور الرابع تم توجيه الأنظار الي دراسة أحد مقومات الإدارة في بلد أو أكثر مع ربطه بالعوامل والمؤثرات البيئية، مثال: دراسة رجز عن تأثير الاعتبارات الحضارية والاجتماعية والفكرية على الإدارة في الولايات المتحدة والفلبين وتايلاند (محمود، 43 (1997:46

\section{ج-تطور حركة الإدارة العامة المقارنة}

بعد الحرب العالمية الثانية "تزايد عدد الكليات والجامعات التي تدرس مساقات في هذا الحقل، والتي تجعل الدراسات المقارنة موضوعاً للدراسات العليا، وقد تحقق اعتراف كثير من الجمعيات العلمية المتخصصة بموضوع الإدارة المقارنة كموضوع متخصص، وتجلي ذلك من خلال تشكيل الجمعية الأمريكية للعلوم السياسية للجنة خاصة بالإدارة المقارنة، وبعدها تأليف جماعة الإدارة المقارنة في سنة 1960 كفرع من الجمعة الأمريكية للإدارة العامة، إذ تلقت هذه الجماعة، تأييداً كبيراً من مؤسسة فورد ساهم في تطورها ونموها، وقامت هذه الجماعة تحت إشراف الاستاذ فرد رجز بدراسات وبرامج دراسية شاملة مثل عقد الندوات العلمية، والمشاريع التعليمية التجريبية وقامت بإدارة حلقات البحث في الاجتماعات المتخصصة، وتنظيم المؤتمرات، وتملس الطرق الكفيلة بتأمين وزيادة الموارد المتاحة والتسهيلات اللازم للأبحاث الميدانية، وقد تبلورت هذه النتائج فيما تم نشره حول موضوع الإدارة المقارنة التي وصلت إلى حجم المجلدات. والتي أدت رغم قصر الفترة الزمنية لها إلى محاولات عدة لإعادة التحليل ومراجعة ما كتب حول الموضوع في أوائل الستينات (هيدي، 17). وقد أكد رجز على ثلاثة تطورات مرت بها الدراسات المقارنة:

التطور الأول: الانتقال من الاتجاه الوصفي Normative إلى الاتجاه التجريبي Emperical التطور الثاني: الانتقال من دراسة الحالات الفردية Idiographic إلى الاتجاه الذي يسعى للوصول لعموميات Nomothetic (ولقد ميز رجز بين أسلوبين: الأول: دراسة أوجه الثبه والاختلاف في درسك

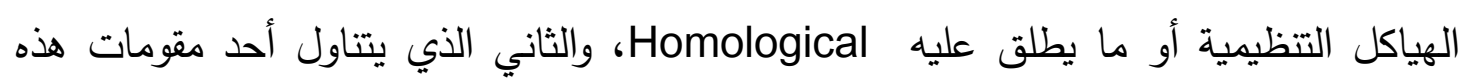
(Analogical الهياكل ويطلق عليه 
التطور الثالث: الانتقال من الدراسات غير الأيكولوجية إلى الدراسات الإيكولوجية (محمود، 51 52

سابعًا- مشكلات وصعوبات دراسة الإدارة العامة المقارنة تتخذ المقارنة التحليلية أكثر من شكل أو مستوي، فهي إما أن تكون "مقارنة الوحدة أو الظاهرة في مرحلتين تاريخيتين مختلفتين في تطورها في مجتمع معين. أو تكون مقارنة ظاهرة أو الوحدة عبر المكان أي في دولتين أو أكثر، وينبغي الإشارة هنا إلى أن القيام ببحوث مقارنة حول ظاهرة أو أكثر في مجتمعات عديدة أمر ضروري لبناء نظرية احتمالية أي الوصول إلى تعميمات أكثر إنرات صدقا" (أفندي، 135: 2012). وتخضع المنهاجية المقارنة لأربعة قواعد كالتالي:

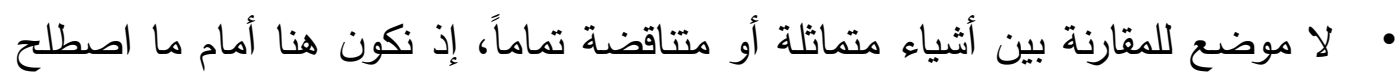
على تسميته بالمقابلة وليس المقارنة، فالظواهر التي يراد إخضاعها للمنهاجية المقارنة لابد وأن تنطوي على نقط اختلاف ونقط التقاء. • • ل اليصح إجراء مقارنات مصطنعة تعتد على تشويه للظواهر أو الحالات محل المقارنة، فكلما بعدت هذه الظواهر أو الحالات عن بعضها البعض مكاناً وزمانا وسياقاً زادت احتمالات التشويه وعدم الدقة في استخلاص النتائج. • • ضرورة اعتماد المقارنة على إطار فكري يتضمن عدداً من المفاهيم المترابطة التي يمكن

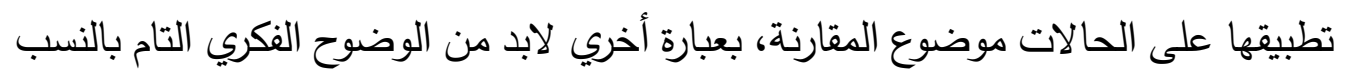
للمتغيرات التي يود الباحث إخضاعها للتحليل المقارن. • ضرورة خضوع الظواهر موضوع المقارنة لمنهج بحث واحد توخياً للدقة العلمية في إظهار جوانب الاتفاق والاختلاف (أفندي، 135: 2012). وعلى الرغم من الأهمية الكبرى للدراسة المقارنة إلا أن وجود جملة من الصعوبات في دراسة الهابة الإدارة العامة المقارنة يمكن أن يحول دون نضجها المأمول، وهي كالتالي: - العوامل الإيكولوجية: صعوبة فهم التقاليد والأحوال الاجتماعية والسياسية والاقتصادية والثقافية في البلاد المختلفة. - الأسلوب: مشكلات عدم التوصل إلى أسلوب علمي متفق عليه لإجراء الدراسات الدقارنة يعتبر من أخطر المشكلات التي تواجه دراسة الإدارة العامة المقارنة. 
- - عدم موضوعية بعض الباحثين حين إجراء الدراسات التي تخص بلاده، ومحاولة إظهار الوضع في دولته على غير حقيقته.

- عدم توافر البيانات خاصة في الدول النامية (شكوك حول مصداقية نتائج الدراسات التي تعتمد على ندرة في المعلومات). - ت - تداخل المتغيرات وسرعة تفاعلها.

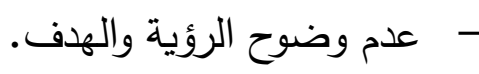

- ياب المفاهيم التكاملية والنقاط المركزية من التحليل والبحوث المقارنة (محمود، 79 $\cdot(1997: 81$

- عدم دقة المصطلحات فلا يوجد بين الدارسين اتفاق حول معنى كثير من المفاهيم بما في ذللك المفاهيم الشائعة كالدولة والحكومة والديموقراطية والسلطة...الخ. - - مشكلة تحديد وحدة المقارنة. - صعوبة بناء المؤشرات (أفندي، 136: 2012). 
حاولت هذه الدراسة - قدر المستطاع - إلقاء بعض الضوء على المدخلين الإيكولوجي والمقارن، مع بعض العوامل البيئية المؤثرة في الإدارة العامة، وهي عوامل مترابطة ومتداخلة ومتصلة

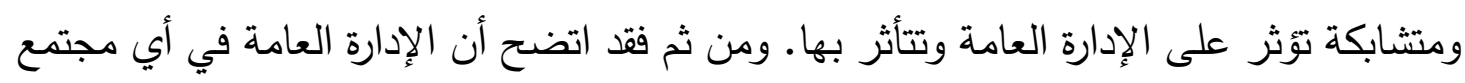
ما هي إلا انعكاس للظروف والأوضاع والتقاليد والعادات والعوامل السياسية والاقتصادية والثقافية والحضارية والتاريخية والجغرافية والدولية والتكنولوجية وغيرها من العوامل. ومن الصعب أن تتصل إلت الإدارة بالتبعية من هذه العوامل المؤثرة. وبالتالي لا يمكن افتراض أن ما تحقق نتائج ايجابية في

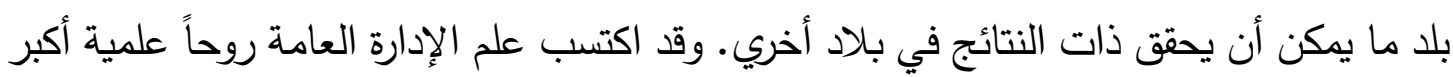
وخفف من التزامه بالطابع الوصفي المعياري السكوني الذي هيمن عليه لفترات وراح يهتم بعلاقته وتفاعلاته الحركية مع علوم الاجتماع والأنثربولوجيا. وقد كان لهذه الأفكار فضل السبق في تحفيز الدول النامية على دراسة البيئة المحيطة بها كبداية لتطوير الإدارة العامة بدون تقليد أو استيراد

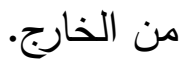
وقد استفادت المنظمات الدولية من هذه الدراسات البيئية في فهم الأشكال والأنواع المختلفة للإدارة العامة في كل دولة، وكيف تتطور العملية الإدارية في المجتمع، والأسباب التي تؤدي إلى نجاح أو فثل نمط معين في دولة ما. وهذا ما ذكرته إدارة الثؤن الاقتصادية والاجتماعية بالأمم المتحدة بقولها إن "المهمة الرئيسة المنوطة بالإدارة العامة تهيئة بيئة مواتية لتعزيز النمو الاقتصادي والتماسك الاجتماعي وحماية البيئة - وهي ركائز التتمية المستدامة الثلاثة، التي تجسدها الأهداف الإنمائية للألفية، فإن إحداث تحول في الإدارة العامة وإصلاحها هي خطوة إيجابية وضرورية من أجل التقدم نحو الأمام" (موقع الأمم المتحدة، إدارة الثؤن الاقتصادية والاجتماعية) ومن ثم يمكننا القول إنه ليس هناك "نظام أمثل للحكومة أو الإدارة العامة. وأن أنظمة الإدارة العامة في المجتمعات المختلفة هي إفراز ونتاج للظروف البيئية التي نشأت ونمت فيها، وبالتالي فإنه من غير الممكن نقل نظام للإدارة العامة ناجح في مجتمع معين إلى مجتمع آخر يختلف عنه لتحقيق نفس النجاح في المجتمع الثاني" (الباز، 53). 


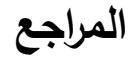

أولا: المراجع باللغة العربية - الثرقاوي على، وسلطان محمد سعيد، (1993): الإدارة العامة، الإسكندرية، الدار الجامعية. - الباز على، (ب.ت) أصول علم الإدارة العامة، الإسكندرية، دار الجامعات المصرية. - أفندي عطية حسين، (2002): الإدارة العامة إطار نظري - مداخل للتطوير وقضايا هامة الإدارة في الممارسة، القاهرة، المؤلف نفسه. ، (2012): حقل الإدارة العامة: مسألة البناء النظري، القاهرة: المؤلف نفسه. - النجار نبيل الحسيني، والمغربي عبد الحميد، (ب.ت): الإدارة العامة النظرية والتطبيق، المنصورة، دار الأصدقاء للطباعة. - بن حبتور عبد العزيز صالح، (2000) الإدارة العامة المقارنة، عمان، الدار العلمية الدولية للنشر والتوزيع، ط1.

- حمدان جمال، (1984) شخصية مصر دراسة في عبقرية المكان، القاهرة، دار الهلال. - دياب حسين عبد الفتاح، (1998) أسس الإدارة العامة: مدخل حديث، القاهرة، شركة البراء. - درويش عبد الكريم، وتكلا ليلي، (1986): أصول الإدارة العامة، القاهرة، مكتبة الأنجلو

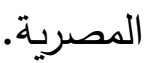

- رشاد عبد الغفار، (2004) مناهج البحث في علم السياسة، القاهرة، مكتب الآداب، ط1. - رسلان نبيل، (1990) الإدارة العامة المقارنة: دراسة تحليلية لبعض القضايا النظرية والمنهجية، السعودية، جامعة الملك عبد العزيز، كلية الاقتصاد والإدارة، مجلة الاقتصاد

$$
\text { والإدارة، العدد الأول. }
$$

- عارف نصر محمد، (1998) نظريات السياسة المقارنة ومنهجية دراسة النظم السياسية العربية: مقاربة إبستمولوجية، الولايات المتحدة الأمريكية، جامعة العلوم الإسلامية والاجتماعية،

- كايم إيميل دور ، (1988) قواعد المنهج في علم الاجتماع، (ترجمة) د. محمود قاسم، د. السيد محمد بدوي، الإسكندرية، دار المعرفة الجامعية.

- هيدي فيريل، (ب.ت) ترجمة: محمد قاسم القريوتي، الإدارة العامة منظور مقارن، عمان، دار 
- محمود محمد فتحي، (1997) الإدارة العامة المقارنة، الرياض، جامعة الملك سعود، ط2.

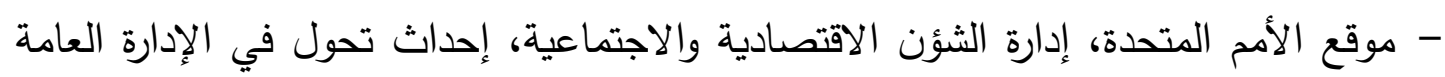
لتحقيق التنمية المستدامة، متاح على الموقع، (الاطلاع: 10 - 11 - 2015).

ثانيا: المراجع باللغة الأجنبية

- Dahl Robert A., (1947) the Science of Public Administration: Three Problems, Public Administration Review, Vol. 7, No. 1, winter.

- Fesler James W. and F. Kettl Donald, (1964) Area and Administration, Alabama, University of Alabama Press.

- Gaus Jone M., (1935) Regional Factors in National Planning and Development, National Recourses Committee, United States Government Printing Office, Washington.

- Gaus Jone M., (1947) Reflections on Public Administration, Alabama, University of Alabama Press.

- Welch Eric and Wong Wilson, (1998) Public Administration in a Global Context: Bridging the Gaps of Theory and Practice between Western and Non-Western Nations, Public Administration Review, Vol. 58, and No.1. 